\title{
Seasonal sea surface height variability in the North Atlantic Ocean
}

\author{
Nicolas Ferry ${ }^{1}$ and Gilles Reverdin \\ LEGOS, Toulouse, France \\ Andreas Oschlies \\ Institut für Meereskunde an der Universität Kiel, Kiel, Germany
}

\begin{abstract}
We investigate the seasonal sea surface height (SSH) variability on large spatial scales in the North Atlantic by using both a numerical simulation and in situ data. First, an ocean general circulation model is run with daily forcing from the European Centre for Medium-Range Weather Forecasts reanalysis. We evaluate the different contributions to the seasonal SSH variability resulting from the surface heat fluxes, advection, salt content variability, deep ocean steric changes, and bottom pressure variability. These terms are compared with estimates from in situ data. North of $20^{\circ} \mathrm{N}$, there is an approximate balance between $h_{Q}$, the air-sea heat flux induced changes in steric height, and SSH variability. The next important component is the advection (its contribution to the annual amplitude is of the order of $1 \mathrm{~cm}$ except near the western boundary); other contributions are found to be smaller. Between $10^{\circ} \mathrm{N}$ and $10^{\circ} \mathrm{S}$ the advection variability induced by the seasonal wind stress cycle is the primary source of SSH variability. We then compare the sea surface height annual harmonic from TOPEX/Poseidon altimetry with the steric effect from the heat flux and with model and/or in situ estimates of the other terms. In many areas north of $20^{\circ} \mathrm{N}$ the balance between $h_{Q}$ and the altimetric SSH seasonal cycle is closed within the uncertainty limit of each of the terms of the SSH budget. However, $h_{Q}$ and the SSH do not balance each other in the eastern North Atlantic, and the results are sensitive to the choice of the heat flux product, suggesting that significant errors, typically $20-40 \mathrm{~W} \mathrm{~m}^{-2}$ for the seasonal cycle amplitude, are present in the meteorological model heat fluxes.
\end{abstract}

\section{Introduction}

Gill and Niiler's [1973] analysis of seasonal variations of upper ocean temperature identified air-sea heat exchange as the prime agent of the seasonal oceanic heat content change. This is particularly expected to hold for large spatial scales away from strong currents and outside of the tropics and has been verified at a few locations with good sampling, for example, in the northeastern Pacific at station Papa [Tabata et al., 1986] and at other weather ship sites [Alexander and Deser, 1995]. Direct investigations of the large-scale ocean heat budget also seem to confirm this hypothesis both in the Pacific [Moisan and Niler, 1998] and in the Atlantic [Cayan, 1992].

Changes in upper ocean temperature and salinity result in a steric contribution to the sea level variability which was observed first by Patullo et al. [1955]. Wang and Koblinsky's [1996] analysis of altimetric sea level data show that this contribution dominates the large-scale seasonal variability in the northeast Atlantic. This is also supported by the work of Chambers et al. [1997] and Stammer [1997]. To illustrate the seasonal signal, we present in Figure 1 the annual harmonic of the large-scale sea

\footnotetext{
${ }^{1}$ Also at Météo France, SCEM/PREVI/MAR, Toulouse, France
}

Copyright 2000 by the American Geophysical Union.

Paper number 1999JC900296.

0148-0227/00/1999JC900296\$09.00 level anomaly from TOPEX/Poseidon (T/P) altimeter measurements for the period October 1992 to September 1997 (data processing is presented in section 3.2). On Figure 1 the annual amplitude is indicated by contours and the phase (date of maximum) is given by the orientation of the vector (January 1 at

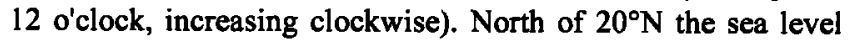
seasonal oscillation reaches a $5 \mathrm{~cm}$ annual amplitude, with somewhat higher values in the Gulf Stream region. The phase is rather constant (maximum in September) over the whole extratropical part of North Atlantic. In the tropics the phase has a stronger spatial variability, and the amplitude varies from $<1$ to 8 $\mathrm{cm}$ at $5^{\circ} \mathrm{N}$, northeast of South America.

Numerical Ocean General Circulation Model (OGCM) experiments at coarse resolution have been used to study the seasonal sea level variability [Stammer et al., 1996; Fukumori et al., 1998]. These numerical models suggest that the deeper steric changes and the bottom pressure changes do not contribute much to the large-scale seasonal sea level variability at midlatitudes, with the main contribution from steric changes induced by the surface heat fluxes. In this study we present a refined test of this hypothesis for the North Atlantic. In particular, the relative magnitude of the different contributions to sea level seasonal variability is carefully evaluated, either directly from observed data or from an OGCM simulation. We have to rely on an OGCM simulation for the advection and bottom pressure seasonal changes which cannot be accurately estimated from in situ observations. These results from the simulation are applied as corrections to real sea level data to investigate if the sea level budget is closed within the observational uncertainties. This is 


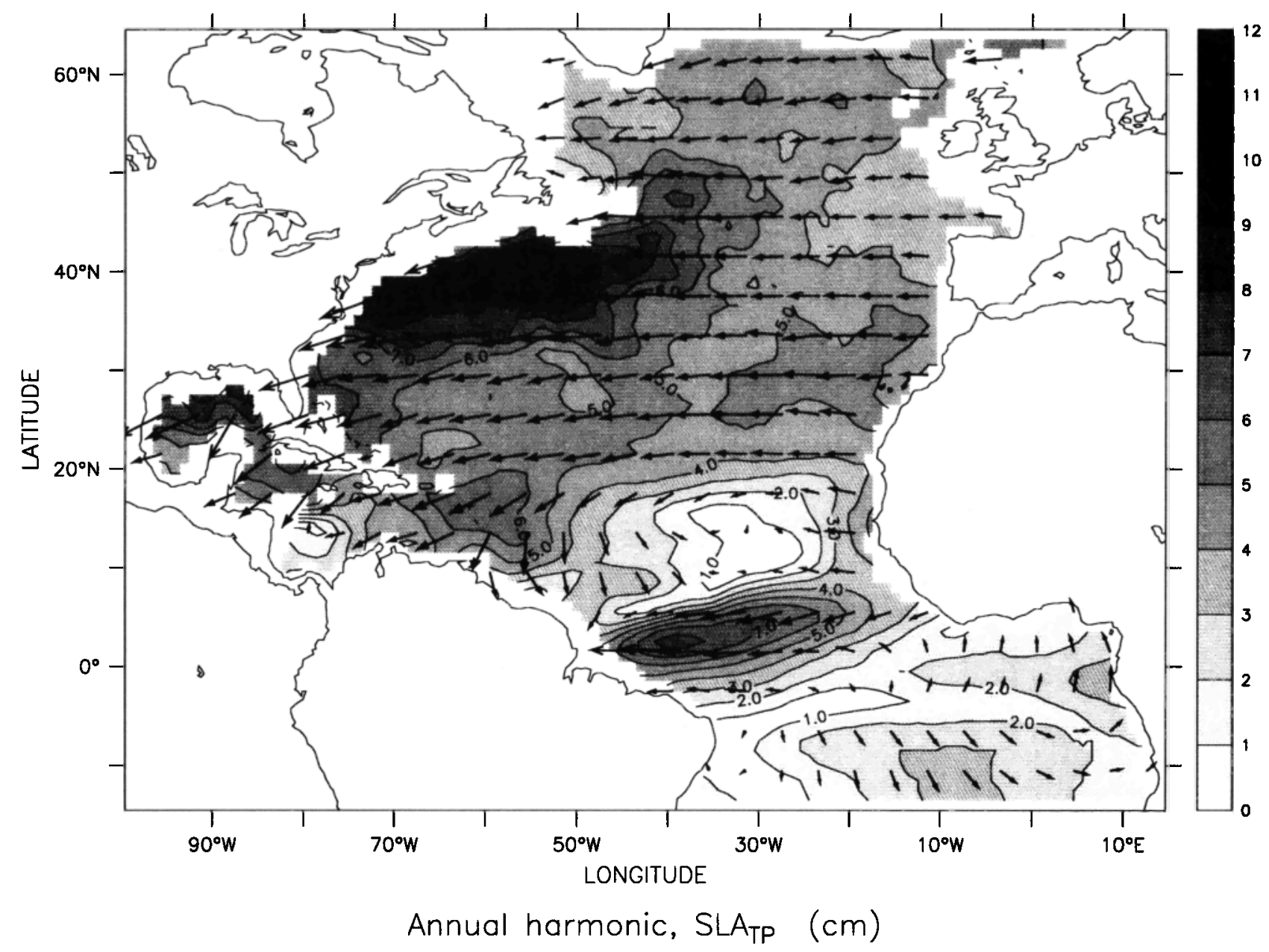

Figure 1. Annual harmonic phase and amplitude of the sea level as measured by TOPEX/Poseidon (T/P) during the period from October 1992 to September 1997. Amplitude is proportional to the length of the vector and the date of the maximum is given by its direction (January 1 at 12 o'clock, increasing clockwise). Contours represent the annual amplitude (in $\mathrm{cm}$ ).

done for the average seasonal cycle from 5 years of T/P altimetric data (October 1992 to September 1997) with the steric effect evaluated from heat fluxes taken from operational meteorological models as well as from climatologies.

The OGCM we use is at a higher resolution $\left(1 / 3^{\circ}\right)$ than some of the previous ones. It includes a mixing scheme that is based on a simplified equation for turbulent kinetic energy. The model is forced with daily European Centre for Medium-Range Weather Forecasts (ECMWF) reanalysis fields. The period of the forcing (1989-1993) is, however, different from the one we investigate for the sea level data. Nonetheless, we expect that the seasonal balance in the simulation should be representative for the T/P period as well. We are also aware of the fact that the observations, in particular the heat fluxes, have errors, which we would like to quantify from the sea level budget.

\section{Methodology}

The basic balance we will discuss can be summarized in the following way:

$$
\langle Q\rangle=\partial_{t}\left\langle\int\left(\rho c_{p} T\right) d z>-\left\langle\int\left(\rho c_{p} \mathrm{ADV}_{D}\right) d z\right\rangle\right. \text {, }
$$

where $Q$ is the air-sea heat flux (positive when received by the ocean), the first term on the right-hand side represents the change in heat content integrated vertically to a depth $z$, and the second term represents the effect of the advective terms on the heal content change of the upper water column (this includes horizontal and vertical advection as well as horizontal and vertical diffusion). Over most of the ocean the density $\rho$ and specific heat $c_{p}$ vary by $<1 \%$, so that assuming that they are constant introduces very little error. Angle brackets represent an appropriate spatial averaging to be defined below. Gill and Niiler [1973] have discussed how the relative magnitude of the advection term $\left\langle\mathrm{ADV}_{T}\right\rangle$ is sensitive to the scale retained; the larger the scale, the less its relative importance.

The heat content can be related to the temperature-induced steric change of the upper water column [e.g. Chambers et al., 1997, Gill and Niiler, 1973] by

$$
\int\left(\rho c_{p} T\right) d z=\rho c_{p} / A\left(\mathrm{SSH}-h_{s}-h_{b c}-h_{b t}\right) \text {, }
$$

where SSH is the sea surface height, $h_{s}$ is the contribution of the steric change related to salinity change assuming a constant temperature, $h_{b c}$ is the contribution of deeper steric change (from depth $z$ to bottom), and $h_{b t}$ is the sea bottom pressure. Here $1 / A$ is a vertically averaged thermal expansion coefficient (see appendix). The equation we will examine is therefore : 


$$
\begin{aligned}
<Q> & =\partial_{t}<\rho c_{p} / A \mathrm{SSH}-\rho c_{p} / A\left(h_{s}+h_{b c}+h_{b t}\right)> \\
& -<\int\left(\rho c_{p} \mathrm{ADV}_{\partial}\right) d z>
\end{aligned}
$$

where we will evaluate to which extent the balance between the first two terms holds. $A$ has a seasonal cycle, and because the average seasonal temperature variability is mostly annual in the North Atlantic [Levitus, 1984], $A$ also varies mostly at the annual harmonic. This will induce a contribution due to nonlinear combination between $1 / A$ and the steric height which will be mostly semiannual. We also checked that nonlinear combinations of semiannual harmonics of these components produce only negligible annual variability. We will only discuss the annual harmonic of the different terms of (1), so that at each individual location $A$ can be taken as a constant (this was tested in the model simulation; see also the discussion in the appendix). We decided not to consider the semi-annual harmonic because of the large error on the sea level semiannual harmonic resulting from aliased tides in the TOPEX-Poseidon data set [Schlax and Chelton, 1994]. Finally, at midlatitudes the semiannual contribution to sea level observations is small and not easily extracted from the background variability.

The results from (1) can be presented in heat flux units (W $\mathrm{m}^{-2}$ ). Here we chose to integrate the equation in time and to present the budget in equivalent sea level units $(\mathrm{cm})$, i.e., the unit of the sea level observation that is central to the study:

$$
\begin{gathered}
A /\left(\rho c_{p}\right) \int(\langle Q\rangle) d t=\left\langle\mathrm{SSH}>-\left\langle\left(h_{s}+h_{b c}+h_{b v}\right)\right\rangle\right. \\
-A \int\left(<\int \mathrm{ADV}_{T} d z>\right) d t .
\end{gathered}
$$

The integration constant has been chosen such that the annual mean of each term is zero. Different spatial scales have been considered. We will present the results for spatial averages in $5^{\circ}$ $\times 7^{\circ}$ latitude by longitude boxes, after removing data on shelves shallower than $300 \mathrm{~m}$. This smooths the fields retaining the main large-scale structures. At midlatitudes this averages out most of the baroclinic wave activity at seasonal to annual periods.

The annual harmonic of the different terms of the model simulation as well as of the observations will be estimated by a least squares fit in a multiple function regression of the time series (annual and semiannual harmonics, trend). The error on the estimated annual harmonic results from the residual to the regression. The estimate on terms for which there is a large unexplained variance will be less certain, and their magnitude will also be less than what would be obtained from a simple Fourier decomposition. This will affect each term differently. It will probably be larger for the bottom pressure term, which in model simulations at midlatitudes, has a large high-frequency component [Fukumori et al., 1998; Stammer et al., 1996]. With the observations we have only hints on some of the terms and some have large errors, in particular the heat fluxes. For the simulation we can quantify all terms of the budget (2). Some of them can deviate significantly from the reality because the average model circulation can be different from what is observed. The seasonal vertical motions depend on the wind forcing, which has some errors, and the simulation of diffusive processes, especially in the extratropics, certainly lacks realism.

After presenting the model simulation used and the data sets from which we estimate the heat budget, we will successively present the different terms of (2) in the model simulation, focusing on whether they are representative of the real ocean. We will then discuss the comparison of TP sea surface height and the heat fluxes for the period from October 1992 to September 1997.

\section{Numerical Simulation and Data Sets}

\subsection{Numerical Simulation}

The ocean model is derived from the high-resolution $\left(1 / 3^{\circ} \times\right.$ $2 / 5^{\circ}$ latitude by longitude) version of the Community Modeling Effort (CME) primitive equation model [Bryan and Holland, 1989]. The domain is the North Atlantic between $15^{\circ} \mathrm{S}$ and $65^{\circ} \mathrm{N}$ with relaxation near the boundaries to the climatological temperature and salinity fields of Levitus [1982]. The present configuration uses a refined vertical grid with 37 levels spaced more closely near the surface. The layer thickness is $11 \mathrm{~m}$ near the surface and increases to $30 \mathrm{~m}$ at $150 \mathrm{~m}$ and $250 \mathrm{~m}$ below 1000 m. A simplified turbulent kinetic energy equation [Blanke and Delecluse, 1993] has been included [Oschlies and Garçon, 1999] which contributes to a more realistic description of turbulent mixing than in the earlier version of the model.

The model is forced by daily wind stress $\tau$ in the momentum equation and by the surface turbulent kinetic energy input $u^{*}$ in the turbulent kinetic equation for the surface layer $\left(u^{*}=(\tau / \rho)^{1 / 2}\right)$. The heat flux at the surface consists of a prescribed flux $Q_{o}$ taken from the daily ECMWF reanalysis plus a relaxation term $R_{T}$ $\left(T_{s}\right.$ obs $\left.-T_{s}\right)$, where $T_{s}$ is the model sea surface temperature (SST) and $T_{s}{ }^{\text {obs }}$ is the weekly SST field [Reynolds and Smith 1995] used by ECMWF for their reanalysis. The relaxation constant $R_{T}$ is computed following Barnier et al. [1995]. It has a geographical dependency similar to the climatology of Barnier et al. [1995] but was chosen to be constant in time ( $R_{T}$ ranges from 20 to 45 $\left.\mathrm{W} \mathrm{m}^{-2} \mathrm{~K}^{-1}\right)$. The freshwater flux at the surface consists simply in a relaxation toward the monthly sea surface salinity climatology from Levitus and Boyer [1994] with a relaxation constant chosen as $1 / 15$ days. For heat and freshwater flux at the surface the relaxation terms guarantee that the simulation is not very far from the observations, at least for the mean state (see Barnier et al. [1995] for a detailed discussion). They can, however, induce lags in the simulated SST and sea surface salinity with respect to the observed variables. They can also affect vertical stratification and therefore mixing and water mass formation, in particular in the Gulf Stream and North Atlantic current areas [New et al., 1995]. The fluxes are applied in the first layer, except for penetrative solar radiation for which clear open ocean water is assumed.

The initial state is taken from a 37 year long simulation of the average seasonal cycle. This long simulation is described by Oschlies and Willebrand [1996] and used Hellerman and Rosenstein [1983] wind stress climatology and surface heat flux parameterization of $\operatorname{Han}$ [1983]. The model is then forced by daily fields from the ECMWF reanalysis for the period 19891993, and the years 1991-1993 are considered in the analysis. The average model circulation for this period presents many realistic current features (Figure 2). However, its Gulf Stream separates from the American continent too far north and a North Atlantic Current (NAC) with a very intense branch flows toward Iceland in the central subarctic gyre. The simulation lacks a well-defined Azores Current in the eastern Atlantic. These defaults are, however, typical of present eddy-permitting models (see the model intercomparison by Dynamics of North Atlantic Models (DYNAMO) Group [1997]). The tropical seasonal circulation is reasonable, which is also typical of other simulations with a similar resolution [Blanke and Delecluse, 1993; Böning and Herrmann, 1994]. This simulation has a too intense convection in the Labrador basin, a reasonable meridional overtuming, and a distribution of late winter mixed layer depths which is relatively realistic, in particular the relatively deep trough extending across 


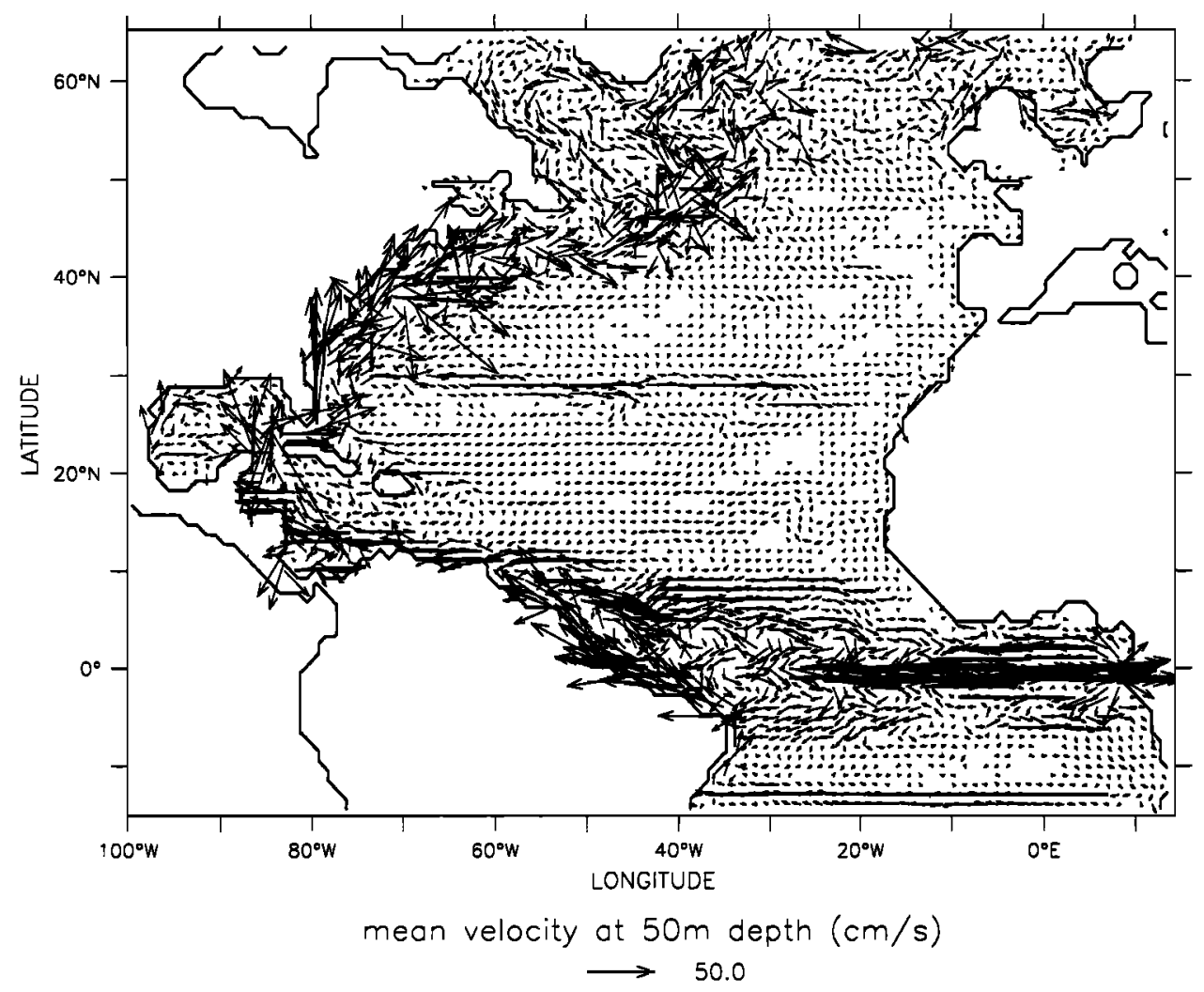

Figure 2. Annual harmonic phase and amplitude of the sea level as measured by TOPEX/Poseidon (T/P) during the period from October 1992 to September 1997. Amplitude is proportional to the length of the vector and the date of the maximum is given by its direction (January 1 at 12 o'clock, increasing clockwise). Contours represent the annual amplitude (in $\mathrm{cm}$ ).

the entire basin along the northem edge of the tropical gyre and the shoaling toward the equator in the subtropical gyre. Figure 3 presents the maximum mixed layer depth $H_{\max }$ attained at each grid point during the 5 year simulation (using a $\Delta \rho=0.125 \mathrm{~kg}$ $\mathrm{m}^{-3}$ criterion), which is much larger than a temporal average of winter mixed layer depths. This often explains why $H_{\max }$ is larger than in climatological fields, for example, Lamb [1984]. There is, however, a tendency to have larger than observed mixed layer depths south of the NAC (which is farther north and west than observed) and also in the eastern North Atlantic, north of $45^{\circ} \mathrm{N}$ and east of $30^{\circ} \mathrm{W}$. This is related to the simulated path of the NAC, which does not penetrate far enough eastward [e.g., Oschlies and Willebrand, 1996]. Nevertheless, we decided to use $H_{\max }$ as the lower boundary for the vertical integration of the model heat equation (equation (2)).

The average deviation of modeled SST from the observed SST is presented for the average winter and summer (Figure 4). It indicates that the differences are larger in winter (except near the equator), an expected result because during the summer, with shallow mixed layers, the relaxation term will be more effective in bringing the SST close to observations. The winter pattern in particular clearly indicates the path of the Gulf Stream being too far to the north, and the resulting strong advection of warm water toward the Irminger and Labrador Seas. Rather large SST deviations are found in the upwelling areas, where the relaxation term has little effect on the sea surface temperature. There is a seasonal cycle in the temperature corrective term, which is much less than the amplitude of the ECMWF heat fluxes.

\subsection{Altimetric Data}

We use a 10 day gridded $\left(0.25^{\circ} \times 0.25^{\circ}\right)$ data set produced by objective mapping of the corrected T/P altimetric sea level data [Le Traon et al., 1997]. The first guess is a spatial average of all the data within a $5^{\circ}$ radius. The usual corrections are applied, in particular the electromagnetic bias correction from Gaspar et al. [1994]. An improved correction for the inverse barometer effect $\left(P-P_{\text {ref }}\right)$ was applied using ECMWF atmospheric sea level pressure $P$ [Dorandeu and Le Traon, 1999]. Instead of assuming a constant reference pressure $P_{\text {ref }}$ equal to $1013.3 \mathrm{mbar}, P_{\text {ref }}$ was calculated as the average sea level pressure over the world oceans, including the Arctic. The principal tidal constituents from the model CSR 3.0 [Eanes and Bettadpur, 1995] are removed (long period tides are not removed). Data on the shelves are removed before spatial filtering. The average seasonal variability is estimated for the period October 1992 to September 1997 (5 years). This estimate is representative of the 5 years selected with an uncertainty which results from the error on the data and from the variability at other frequencies. For the spatially averaged data we consider, this results in an rms uncertainty in the annual harmonic amplitude and phase of $6 \%$ and $4^{\circ}$ in the eastern Atlantic to $6 \%$ and $3{ }^{\circ}$ in the Gulf Stream area (see section 5 for a description of this uncertainty estimation). There is also the possibility that this product has seasonally dependent biases. On the basis of comparisons with tide gauge sites in the North Atlantic (in particular at Ponta Delgada, Azores) we estimate that the monthly fields are accurate to within $1.6 \mathrm{~cm}$ ms difference, 


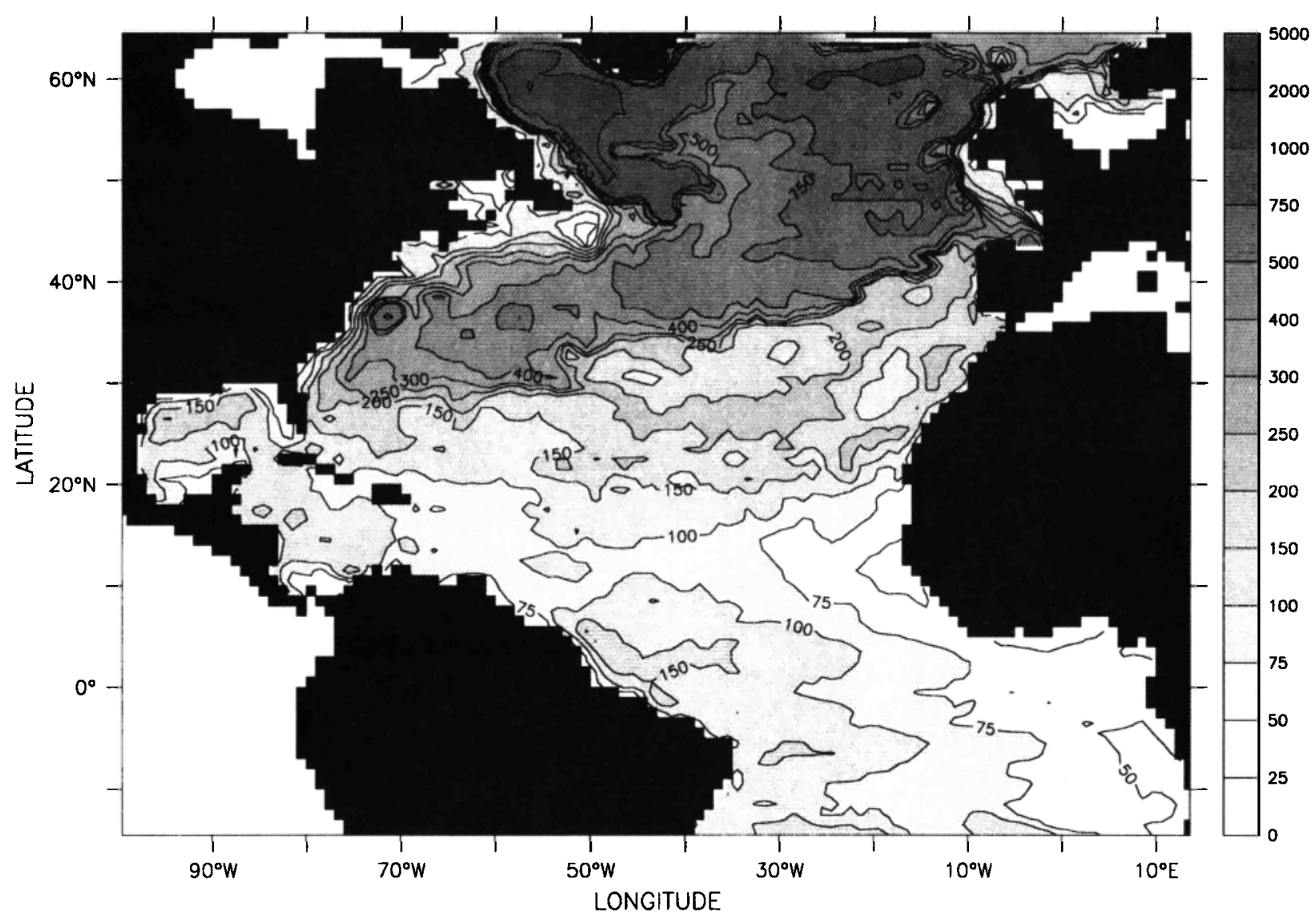

Figure 3. Maximum mixed layer depth $H_{\max }$ (m) during a 5 year integration of the model. $\mathrm{A} \Delta \rho=0.125 \mathrm{~kg} \mathrm{~m}^{-3}$ criterion is used to determine the mixed layer depth.

including systematic seasonal biases. Annual amplitude and phase of Ponta Delgada tide gauge and T/P measurements at that location were found to be in agreement to within $1 \mathrm{~mm}(\sim 2 \%$ of the annual amplitude) and $4^{\circ}$, respectively.

\subsection{Other In Situ Data}

Because of uncertainties on the model circulation we will also use a data set of near-surface currents to independently estimate the effect of horizontal advection. Horizontal advection of heat is estimated from upper ocean currents and monthly SST maps [Reynolds and Smith, 1995] by assuming a $150 \mathrm{~m}$ deep mixed layer and letting the currents advect the SST field. This very simple calculation does not properly take into account the advection below the seasonally varying mixed layer, which is difficult to estimate from very scarce in situ temperature profiles and velocity fields. The average currents are constructed from drifter velocities provided by NOAA/Atlantic Oceanographic and Meteorological Laboratory (AOML) and the Ice Patrol. The drifters are all drogued World Ocean Circulation Experiment (WOCE) drifters and should be current followers to within $1 \mathrm{~cm}$ $\mathrm{s}^{-1}$ for typical wind conditions in the North Atlantic [Niiler et al., 1995]. Most of the drifters are drogued at $15 \mathrm{~m}$ (the Ice Patrol drifters were, however, often drogued at $50 \mathrm{~m}$ ). Different regions have been sampled at different times, but a large part of the data corresponds to the period 1993-1998 and is therefore nearly simultaneous with the altimetric data set. Most major currents north of $25^{\circ} \mathrm{N}$ have been sampled during that period, with the exception of the Gulf Stream south of Cape Hatteras. The Gulf Stream, after its separation off Cape Hatteras, and the NAC are well sampled, but because of the large eddy variability in this area the average currents still have large uncertainties. One should also mention that a large part of the drifters in the Gulf Stream have entered the current from the north (major deployments were in the Mid-Atlantic Bight and in the vicinity of George Bank).

The data have been gridded on a $0.5^{\circ} \times 2^{\circ}$ latitude by longitude grid, which captures a large part of the structure in the average currents and their quasi-stationary meanders or eddies (for instance, in the NAC, east of the Grand Banks). These boxes are large enough so that most of them north of $25^{\circ} \mathrm{N}$ have at least 15 days of drifter data, which we find to be an absolute minimum to approach the average circulation in the presence of the energetic eddy field. An illustration of the resulting circulation in the eastern Atlantic is presented in Figure 5, which shows few currents $>5 \mathrm{~cm} \mathrm{~s}^{-1}$. The NAC is well represented with strong eastward current branches at $34.5^{\circ}$ (the Azores Current), $45^{\circ}$, and $52^{\circ} \mathrm{N}$. We also decided to substract an averaged Ekman component of the current at $15 \mathrm{~m}$ using a method described by van Meurs and Niller [1997]. The wind stress used for this computation is taken from the ERS weekly wind stress product.

To reconstruct the current field at any given time, we add to this average current the geostrophic current deviations based on smoothed altimetric sea level fields and an Ekman velocity distributed over the $150 \mathrm{~m}$ layer which is estimated from the ERS weekly wind stress product. In order to justify the calculation of 


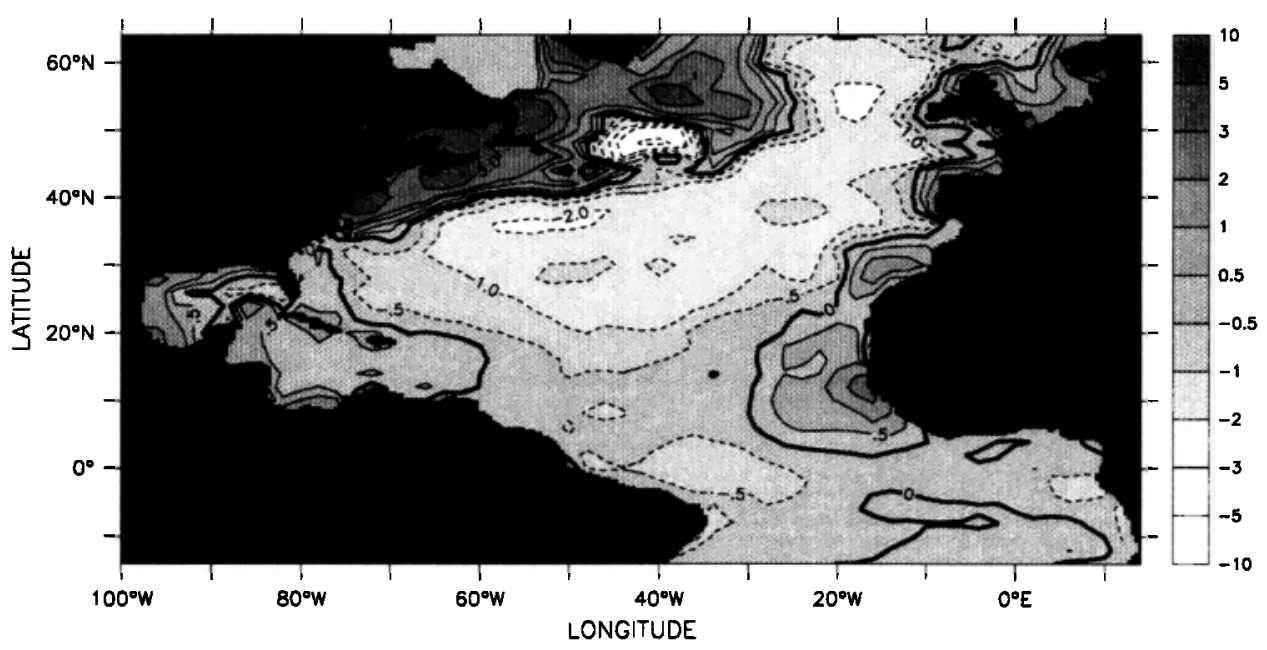

SST model-Reynolds, for winter $(J-F-M)$ deg. C

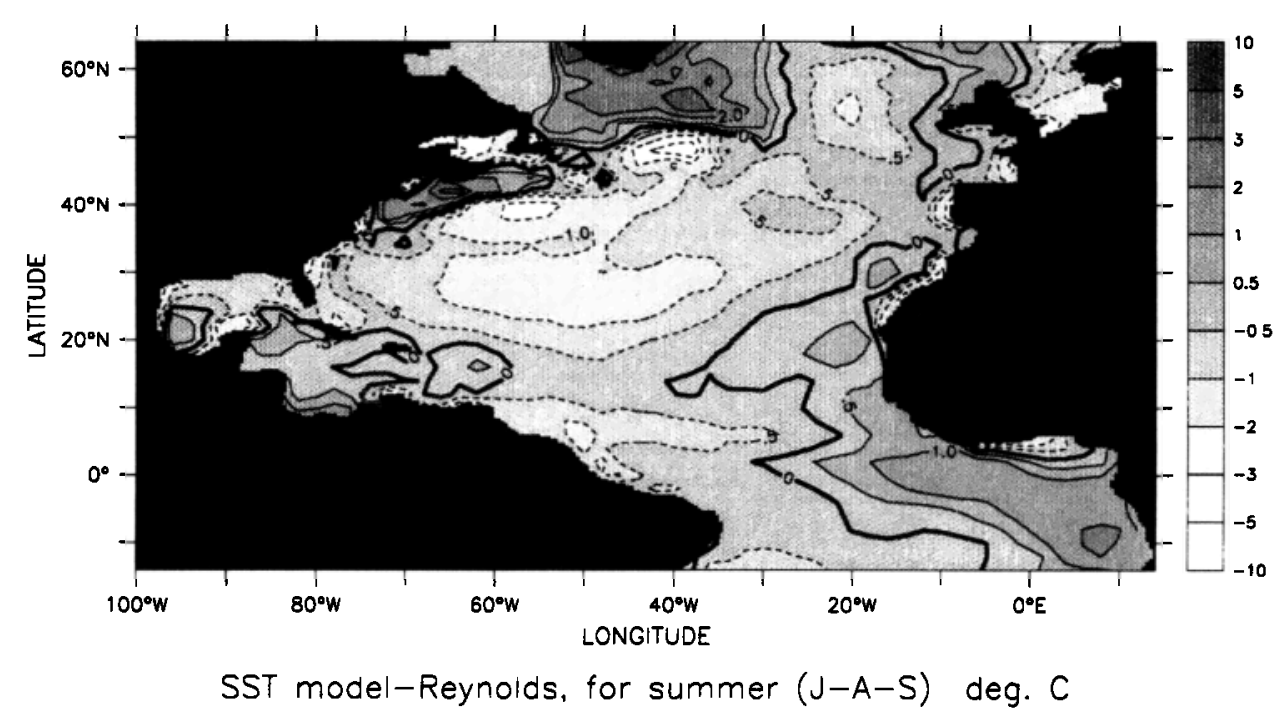

Figure 4. Deviation of the modeled SST from the observed SST for the last 3 years of simulation averaged over (a) winter (January-March) and (b) summer (June-September) months (in ${ }^{\circ} \mathrm{C}$ ).

advection described above, we have performed a comparison between the horizontal advection diagnosed in the model and a composite advection product calculated in the same manner described in this section and using model outputs. The results show that the composite advection field overestimates the amplitude of the advection field over the whole basin. It is, however, interesting to consider this advection estimate from data because it is completely independent from the model simulation. It should be an upper boundary for the real horizontal advection annual amplitude in the upper layers of the ocean.

We have also used temperature profiles from expandable bathythermographs (XBT) data in an area which has been regularly sampled since 1992 in the eastern North Atlantic (between $40^{\circ}$ and $25^{\circ} \mathrm{N}$ and west of $40^{\circ} \mathrm{W}$ ) to estimate directly the seasonal changes in steric height above $700 \mathrm{~m}$, separating the contributions of the near-surface layer above the winter thermocline and of the deeper layer.

\section{Sea Level Budget}

\subsection{Annual Heat Fluxes and Sea Level From the Model Simulation}

The simulated SSH annual harmonic (Figure 6b) presents its largest variability near the model Gulf Stream $(>9 \mathrm{~cm})$ with a maximum near day 270 . In the subtropical gyre, there is a large band with an amplitude between 4 and $5 \mathrm{~cm}$ (and an earlier phase of the maximum near day 240) with amplitudes decreasing toward the northeast and south of $20^{\circ} \mathrm{N}$. Closer to the equator, there is more structure in the field with two bands of larger variability centered near $10^{\circ} \mathrm{N}$ and near the equator in the western Atlantic and an area of large variability in the Gulf of Guinea.

The steric variability induced by the simulated heat flux (Figure 6a) also presents a maximum amplitude in the Gulf Stream with an amplitude decreasing regularly toward the south 


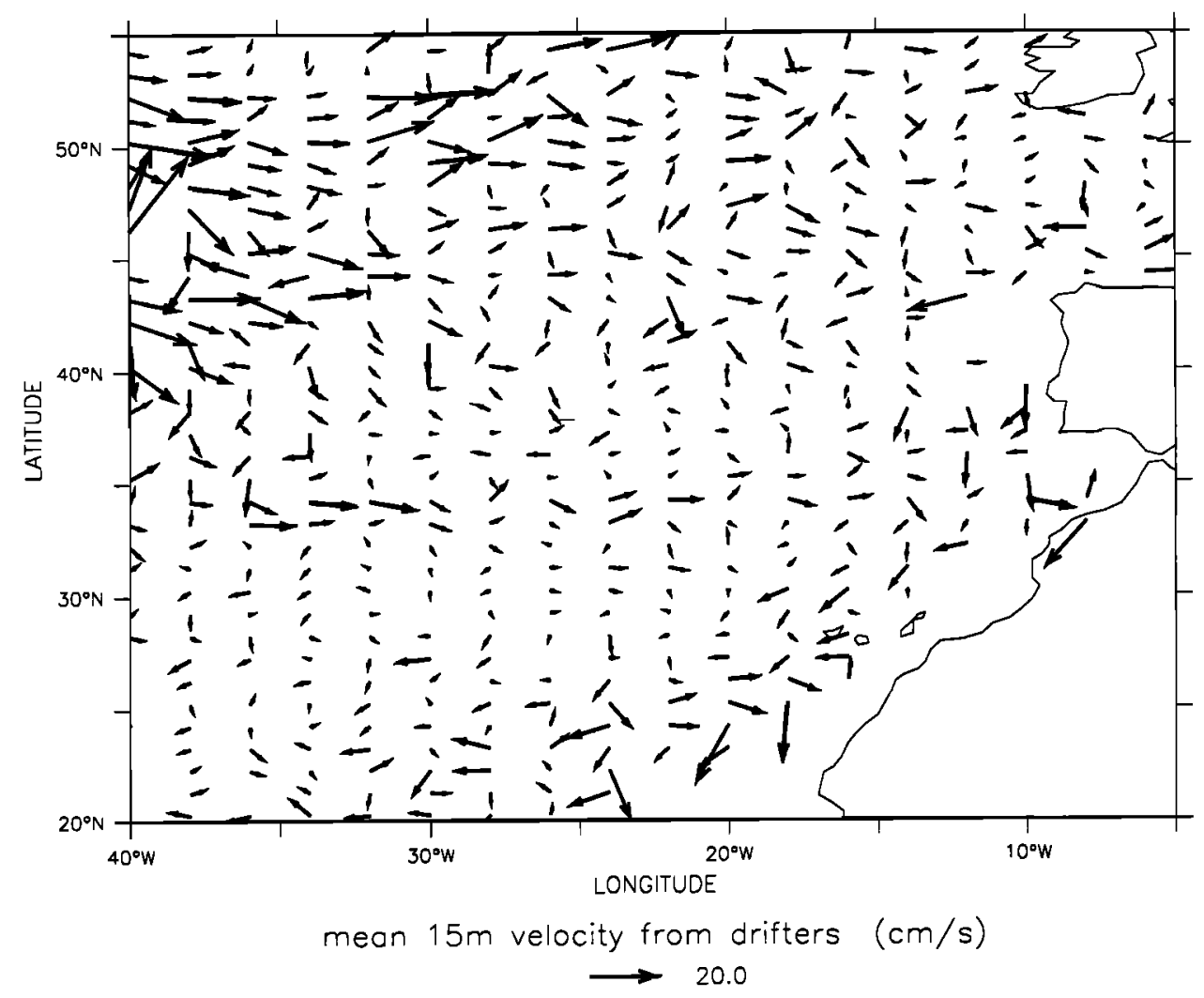

Figure 5. Mean currents at $15 \mathrm{~m}$ depth gridded on a $2^{\circ} \times 0.5^{\circ}$ longitude by latitude grid from drifter velocities in 1993-1998 in the eastern North Atlantic $\left(\mathrm{cm} \mathrm{s}^{-1}\right)$.

and presenting a minimum near the equator. North of $20^{\circ} \mathrm{N}$, the amplitude is often less than the one in the sea level (except in the eastern North Atlantic), but the phase agrees very well with that of the sea level. The difference between the annual harmonic of sea level and the one in the steric variability induced by the heat fluxes is presented normalized by the amplitude of the sea level annual harmonic on Figure $6 \mathrm{c}$ and can be considered an estimate of the unexplained variance. Within $15^{\circ}-20^{\circ}$ of the equator this ratio is large, and a large part of the signal in sea level cannot be explained by the heat fluxes. Farther north, there is a large area in the range 0.1-0.2, increasing north of the Gulf Stream in the northwest Atlantic to $>0.3$. In the simulation, where the budget is perfectly balanced, this has to be explained by the other terms of (2).

\subsection{Advection Term}

First, we consider the advection term of (2) integrated from the surface down to $H_{\max }$ (Figure 7a) in the model simulation. This term has an amplitude of $<0.5 \mathrm{~cm}$ in a large part of the domain (equivalent to $<20 \mathrm{~W} \mathrm{~m}^{-2}$ ) where it represents $<20 \%$ of the sea level signal (Figure $7 \mathrm{~b}$ ). The rms uncertainty on the amplitude is $<0.25 \mathrm{~cm}$ in large parts of the eastem Atlantic and subtropics. The advection term is larger in the Gulf Stream, where the maximum is reached near day $220-270$, which suggests that it contributes to a larger sea level variability than one would expect from the heat flux alone. It increases near the equator and in the Gulf Stream. The contribution due to advection is weakest in the eastern North Atlantic, where its does not exceed 0.25-0.5 $\mathrm{cm}$. In the tropics the advection term presents a structure similar to the one in sea level but with smaller amplitudes. There it originates mostly from the vertical advection associated with the seasonal displacement of the thermocline, resulting from the seasonal wind forcing [Merle and Arnault, 1985]. In that sense, it should be considered together with the deeper steric contribution $h_{b c}$ (Figure 8a), which has a similar structure (see below).

The only term we can estimate from data is horizontal advection (the dominant contribution in the model simulation north of $20^{\circ} \mathrm{N}$ ). This is done for the 5 years from October 1993 to September 1997 as described in section 3.3. The annual harmonic of the estimated advection is computed and smoothed on the same grid as the model results, and we separate the component associated with the geostrophic currents (Figure 7c) from the part associated with the variable Ekman component (Figure 7d). The contribution of the Ekman currents is usually less than the one of the geostrophic currents, and they often have the same phase. Not surprisingly, the two terms have large values in the Gulf Stream and smaller values in the eastem Atlantic. In the western Atlantic, this estimated horizontal advection has amplitude and phase somewhat similar to $\left(A \int<\int \mathrm{ADV}_{T} d z>d t\right)$ in the model simulation, but it is much less important north of $50^{\circ} \mathrm{N}$ (clearly, this suggests a deficiency of the simulation in the subarctic gyre). In the data, there is a suggestion of a tongue of larger $(0.5-1 \mathrm{~cm})$ variability near $40^{\circ}-45^{\circ} \mathrm{N}$ toward the eastern Atlantic, which is not found in the simulation (and with a different phase). There is also a band of large values $(1 \mathrm{~cm})$ near $20^{\circ} \mathrm{N}$ west of $40^{\circ} \mathrm{W}$, which is not found in the model simulation and which is certainly 


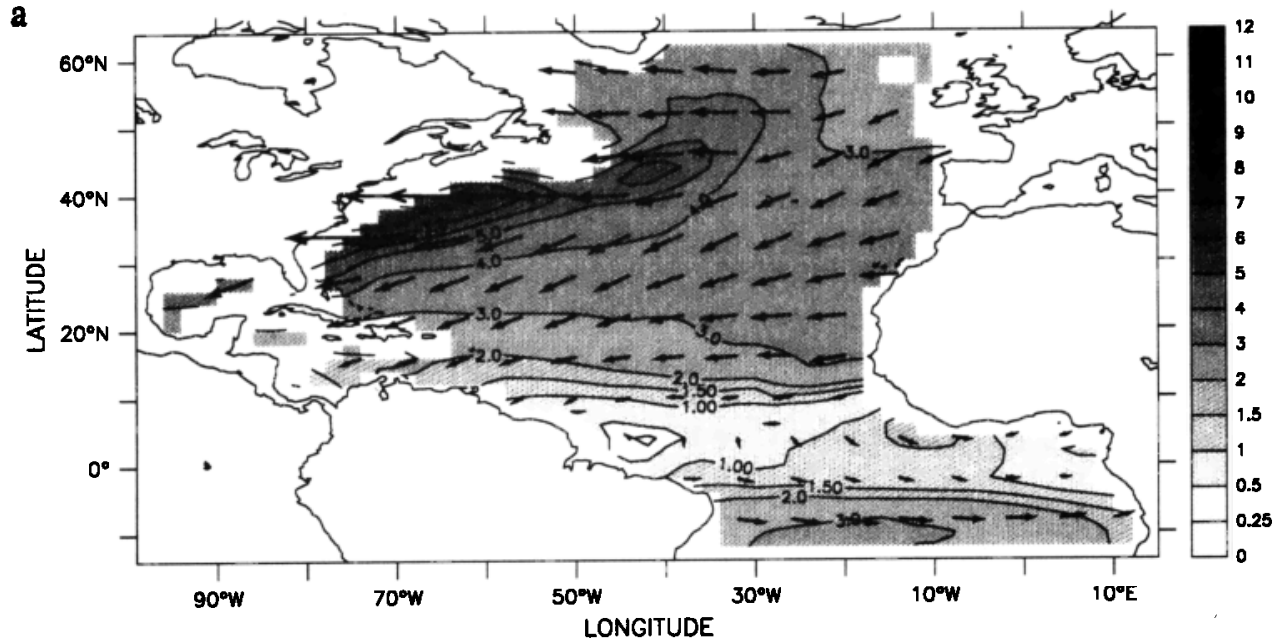

Annual harmonic $h_{\text {Qnet }}$ model $(\mathrm{cm})$
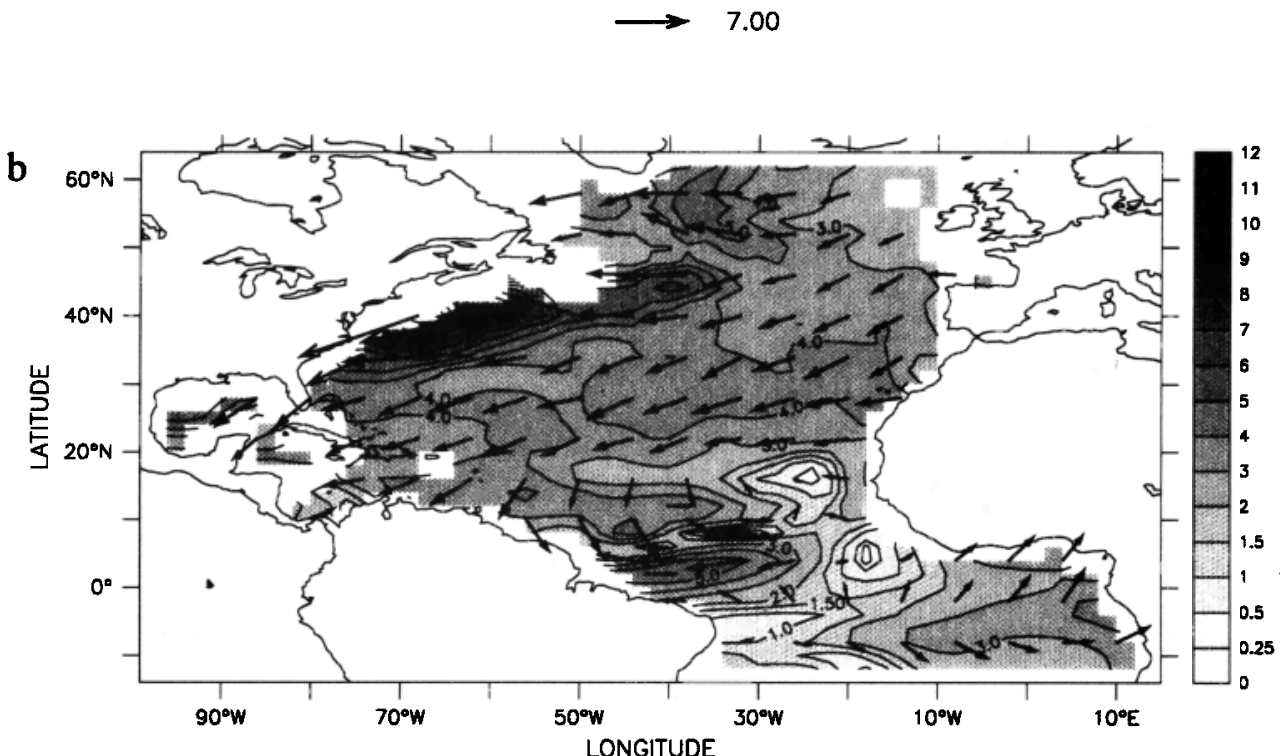

Annual harmonic SSH model (cm)
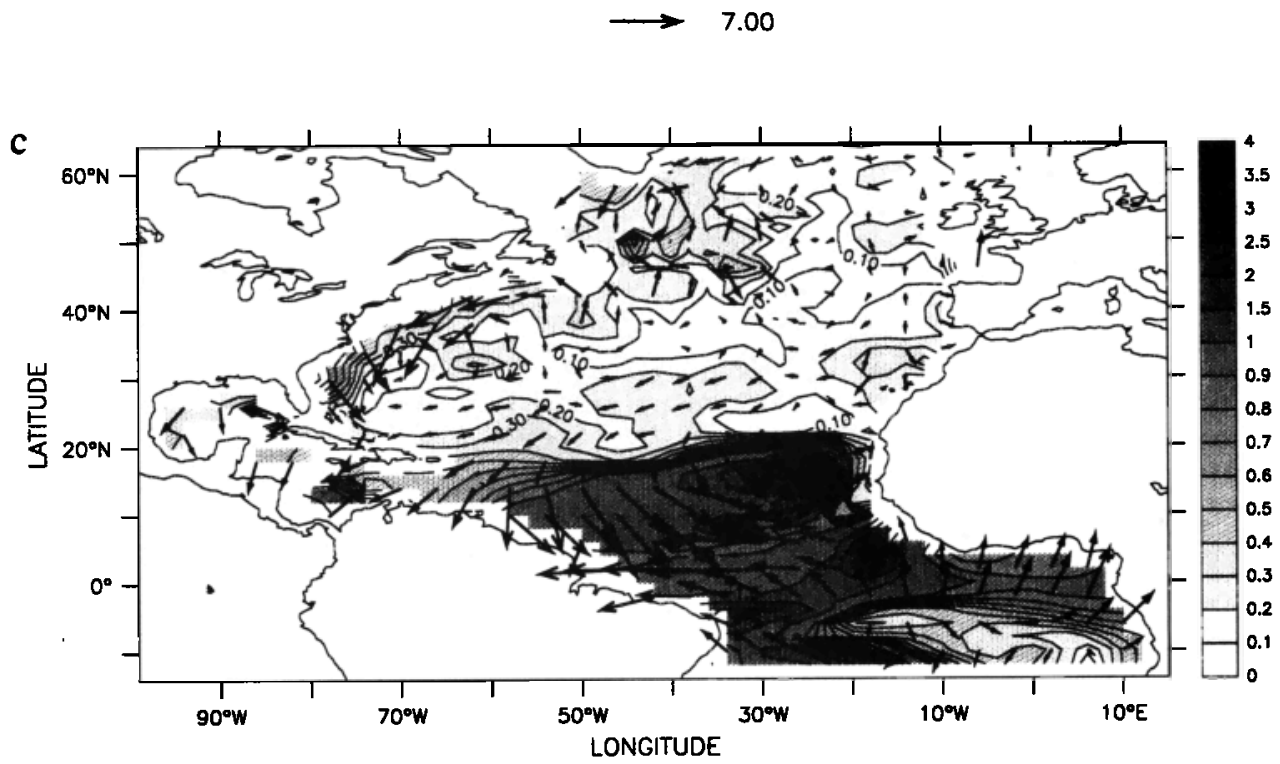


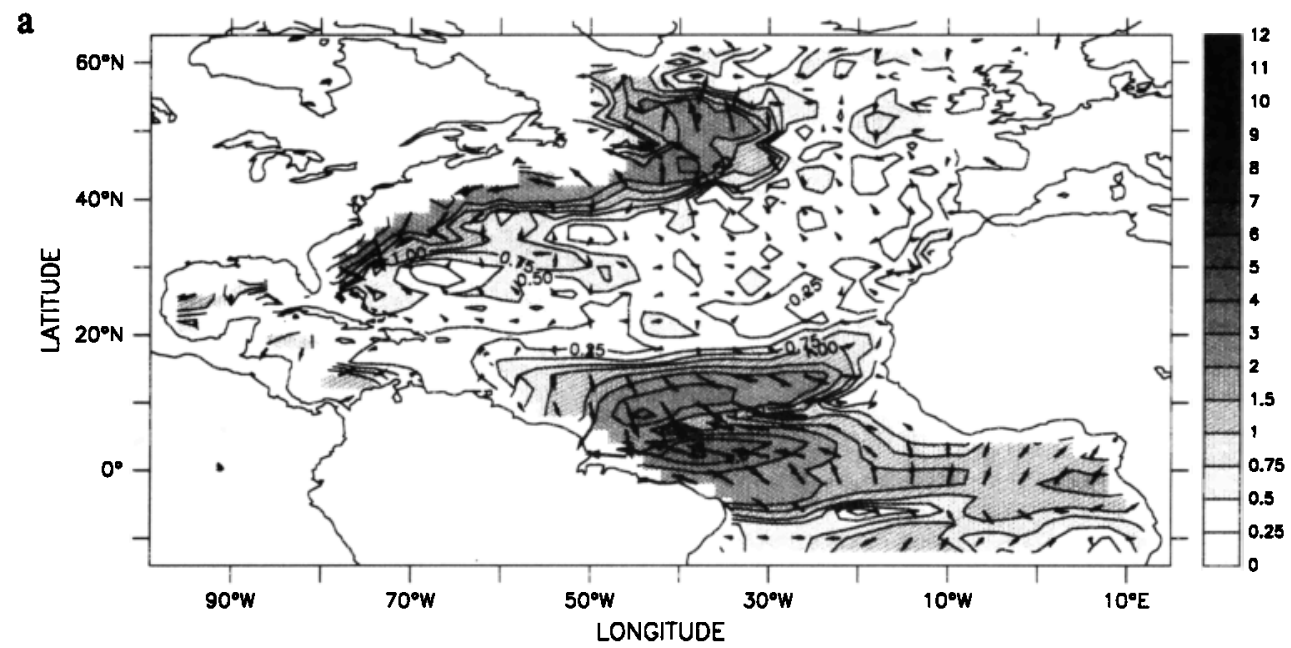

Annual harmonic, Advection (cm)

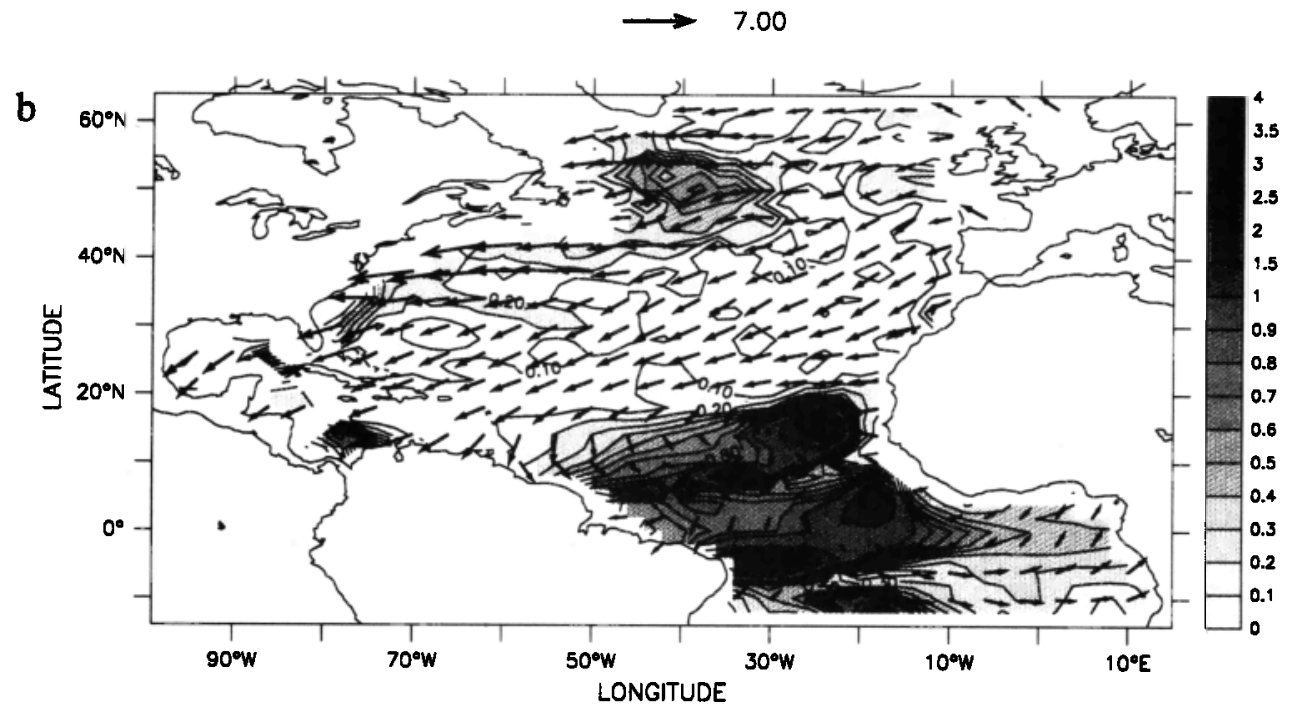

Figure 7. (a) Same as Figure $6 \mathrm{a}$ but for the simulated advection (in $\mathrm{cm}$ ). (b) Annual harmonic of the simulated advection normalized by the annual harmonic amplitude of the simulated SSH. The length of the vectors is proportional to the nonnormalized difference (in $\mathrm{cm}$ ). (c) Same as Figure 7a but for in situ estimate of geostrophic advection estimated from data. (d) Same as Figure 7a but for in situ estimate of Ekman advection estimated from data.

due to an undersampling of mean velocity by drifting buoys in this area and to an incorrect description of the vertical structure of the temperature gradients. The uncertainty on this estimate from data is difficult to ascertain, as it originates also from systematic errors in the average current field and in the estimate of the vertical structure of currents and horizontal temperature gradients.

\subsection{Deeper Steric Contribution}

In the tropics the deeper steric contribution $h_{b c}$ in the model simulation (Figure 8a) has a structure similar to the one of the advection term. This is expected because the advection term in the tropics results, to a large extent, from vertical advection of the thermocline, which also contributes greatly to $h_{b c}$. Notice that the maximum amplitude near $10^{\circ} \mathrm{N}$ extends farther west than for the advection term and that it has a smaller amplitude in the western equatorial Atlantic. The deeper steric contribution is small almost everywhere north of $20^{\circ} \mathrm{N}(0.25 \mathrm{~cm}$ or less $)$, where it is rarely significant (based on the rms uncertainty) and where it is always smaller than the advection term.

Here $h_{b c}$ can be compared with estimates from climatological monthly temperature and salinity fields [Levitus and Boyer, 1994]

Figure 6. (a) Annual harmonic phase and amplitude of the heat flux induced steric height of the model. Note that this component includes the relaxation term of the surface heat flux parameterization. Amplitude is proportional to the length of the vector and the date of maximum steric height is given by its direction (January 1 at 12 o'clock, increasing clockwise). Contours represent the annual amplitude (in $\mathrm{cm}$ ). (b) Same as Figure 6 a but for the simulated sea surface height (SSH). (c) Difference between the model SSH and heat flux induced steric height annual harmonics normalized by the amplitude of SSH. The length of the vectors is proportional to the nonnormalized difference (in $\mathrm{cm}$ ). 


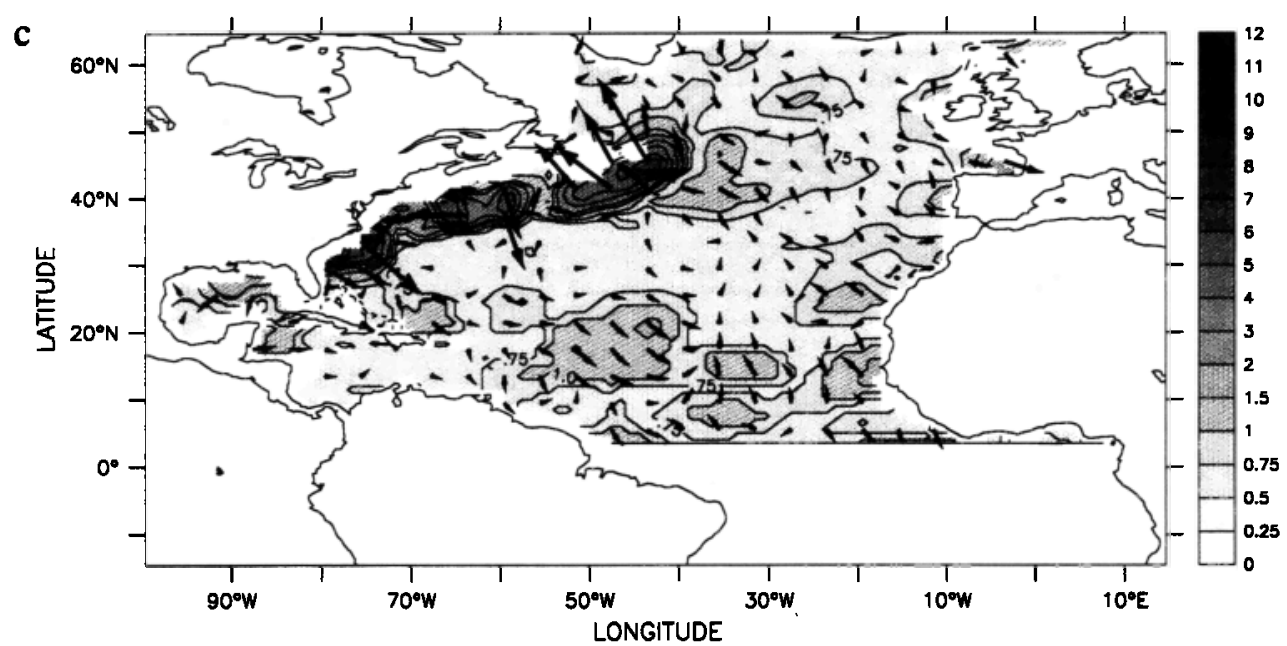

Annual harmonic, geostrophic odvection $(\mathrm{cm})$

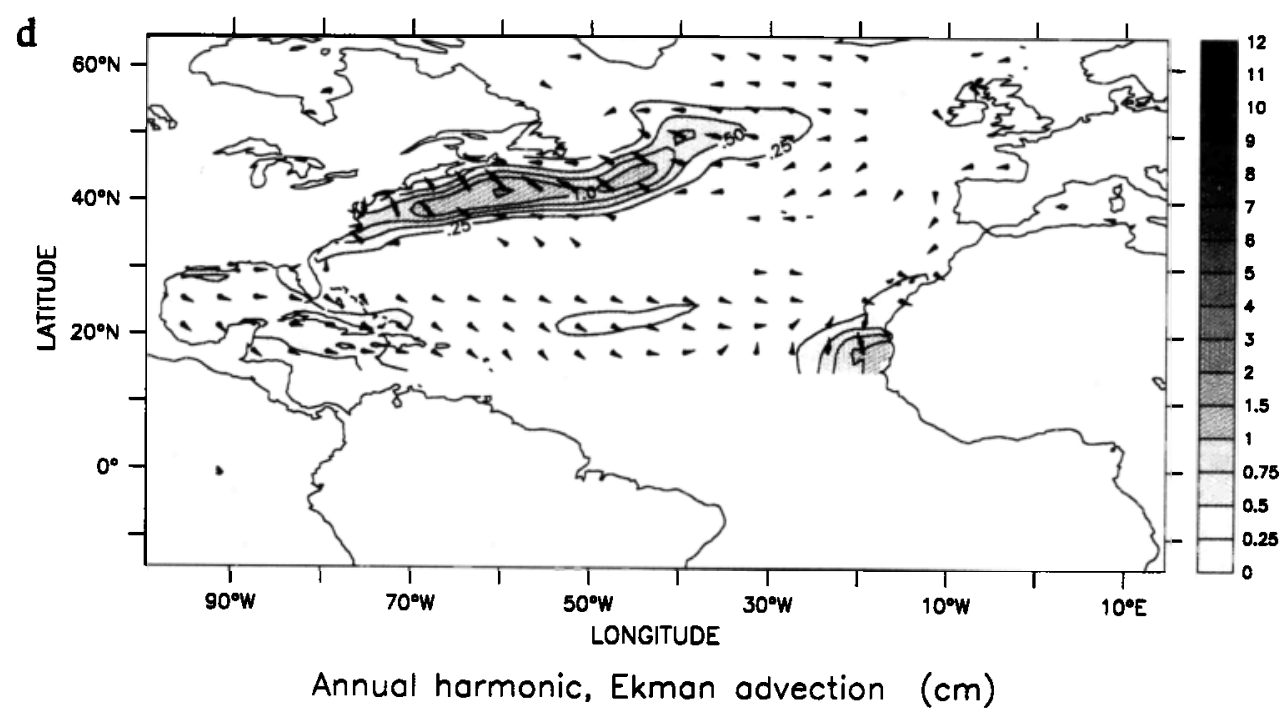

Figure 7. (continued)

between $H_{\max }$ and $1000 \mathrm{~m}$. Notice that the climatological temperature fields are rather well constrained, at least above $800 \mathrm{~m}$, but that the salinity fields are based on a rather coarse sampling which does not constrain well the monthly fields, resulting in larger errors. The calculation of $H_{\max }$ is done using the same mixed layer criterion as for the model but is based on the average monthly fields. Mesoscale processes, interannual variability in the surface forcing, and baroclinic wave propagation all contribute to a deeper $H_{\max }$ in the model than in the Levitus and Boyer [1994] climatology. However, we believe that similar physical processes are present in the simulation and in the climatology at the annual period, independent from the depth of the mixed layer.

This climatological estimate (Figure $8 \mathrm{~b}$ ) presents a large spatial variability at midlatitudes. Its annual harmonic has an amplitude $>1 \mathrm{~cm}$ south of $30^{\circ} \mathrm{N}$, as well as near $35^{\circ} \mathrm{N}$ west of Gibraltar and between $35^{\circ}$ and $50^{\circ} \mathrm{W}$ (the phase is quite different between the two areas). These results are coherent with previous studies (for example, at $33^{\circ} \mathrm{N}, 22^{\circ} \mathrm{W}$, Stramma and Siedler [1988] document a warming in the early months of the year at $200 \mathrm{~m}$ ). There is also a large variability north of the Gulf Stream which is not found for the equivalent model term, as for most of the variability north of $20^{\circ} \mathrm{N}$. South of $20^{\circ} \mathrm{N}$, there is more similarity between the two fields, although the large amplitudes near $10^{\circ} \mathrm{N}$ in the data are confined farther west than in the simulation, and the western equatorial maximum is more present in the climatology. The latter is coherent with other analyses of the equatorial Atlantic seasonal cycle [Merle, 1980; Merle and Arnault, 1985].

To complement this analysis of the climatology, it is possible to estimate the seasonal steric variability integrated to $700 \mathrm{~m}$ on the basis of individual temperature profiles (XBT). We chose profiles from the years corresponding to the altimeter data (October 1992 to September 1997), but we could similarly have considered data collected for the years of the simulation (19891993) with little difference. In the northeast Atlantic, the data coverage is mainly adequate between $40^{\circ}$ and $20^{\circ} \mathrm{N}$, east of $45^{\circ} \mathrm{W}$. Except in the northwest corner of this domain, the winter mixed layer depth is usually $<150 \mathrm{~m}$, which we select as the lower boundary of the upper layer. The annual steric contribution of the layer above $150 \mathrm{~m}$ is relatively uniform, with smaller values in the eastern part of the domain as well as south of $25^{\circ} \mathrm{N}$ 


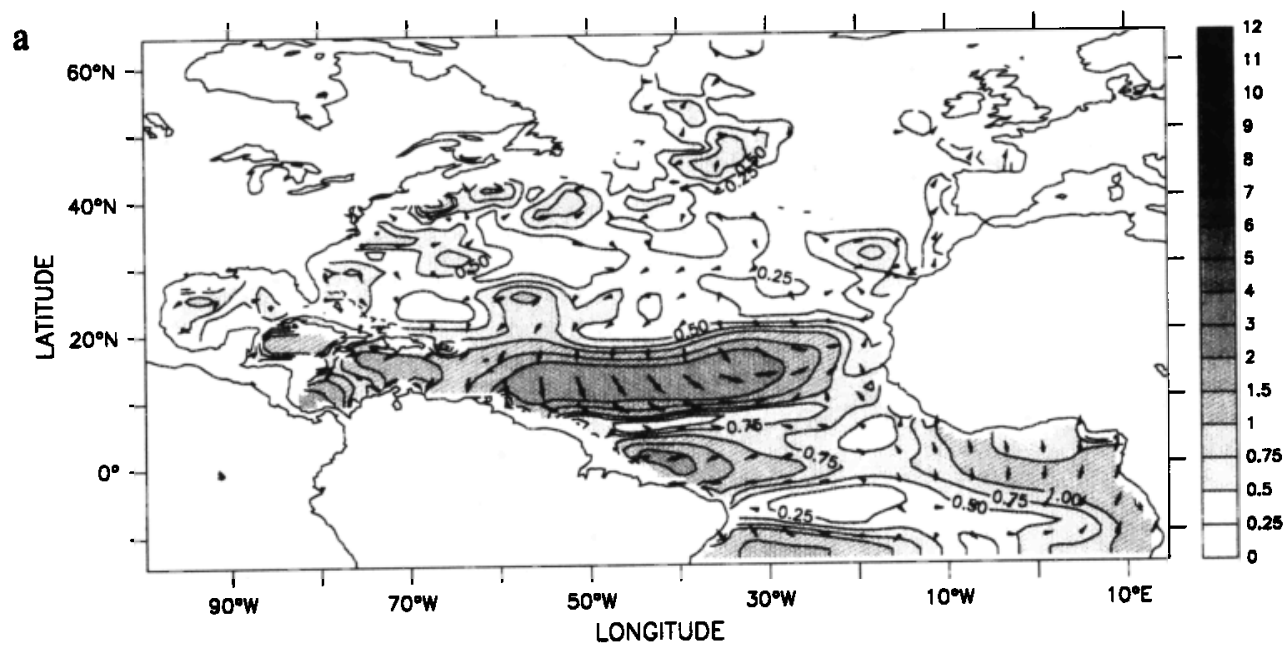

Annual harmonic, $h_{b e}(\mathrm{~cm})$

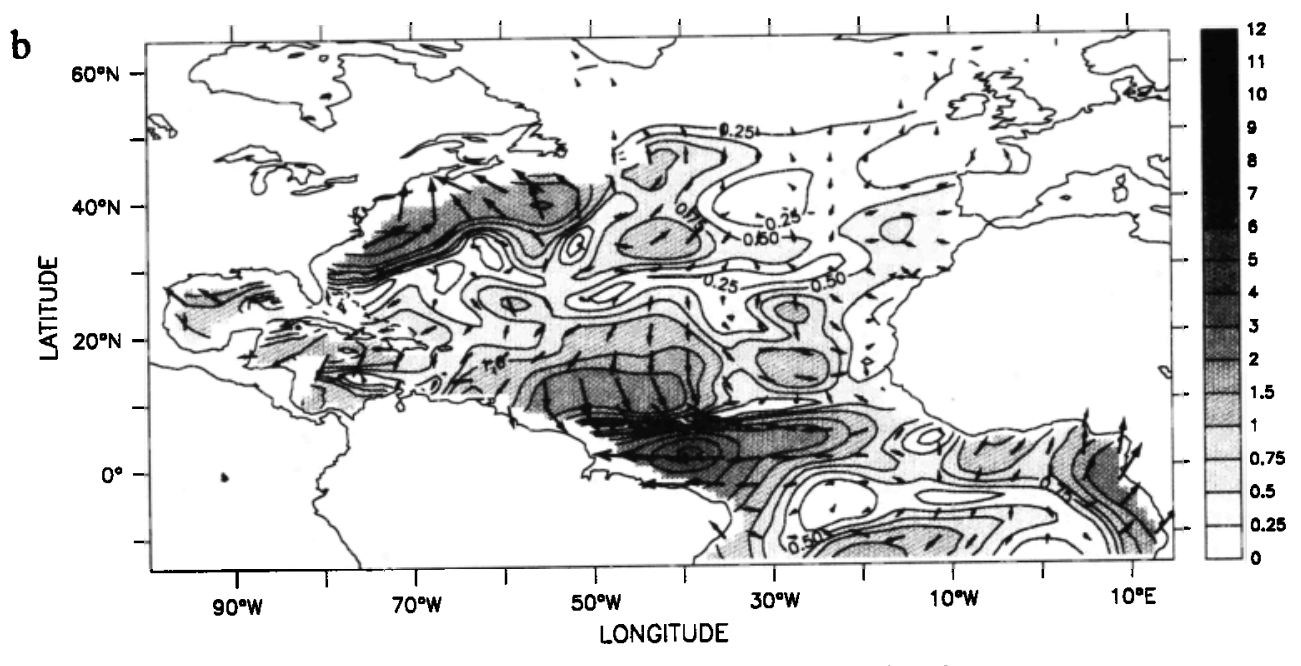

Annual harmonic, $h_{b c}$ Levitus $(\mathrm{cm})$

Figure 8. (a) Same as Figure 6a but for the simulated deep steric component $h_{b c}$ (b) Same as Figure 8a but for the monthly Levitus and Boyer [1994] climatology. Steric height is integrated between $H_{\max }$ (obtained from Levitus and Boyer [1994] atlas) and $1000 \mathrm{~m}$. (c) Upper ocean $(0-150 \mathrm{~m})$ steric height annual harmonic from expandable bathythermographs (XBT) profiles collected during 1992-1997 (in cm). Profiles are binned in $5^{\circ} \times 4^{\circ}$ longitude by latitude boxes. (d) Subsurface (150-700 m) steric height annual harmonic from (XBT) profiles.

(Figure 7c). This is very similar to what is found with the climatology. Other details of the distribution are within the uncertainty caused by the sampling and the eddy variability. The contribution to steric sea level below $150 \mathrm{~m}$ is much less, with larger uncertainties, in particular in the central part of the domain, which is not as well sampled (Figure 7d). There is, however, some indication for a seasonal cycle in the northeastern part of the domain (north of $36^{\circ} \mathrm{N}$ ) with maximum values in March ( $<1$ $\mathrm{cm}$ ). This is larger than what is found in the simulation and could result from the seasonal Ekman pumping. This component is smaller in the model simulation probably because the depth of integration for the upper layer is particularly large ( $300 \mathrm{~m}$; see Figure 3) and thus includes a large part of the Ekman pumping component near the thermocline.

\subsection{Surface Salinity}

In the model simulation the contribution of salinity variations in the mixed layer, $h_{s}$, is also smaller than the advective term but is well defined with only small rms uncertainties. It can reach 1 $\mathrm{cm}$ near and north of the model Gulf Stream (Figure 9a). It is also rather large near $15^{\circ} \mathrm{N}$ and, in particular, north of Venezuela. The salinity changes in the upper layer result from a combination of advection-diffusion and surface forcing (relaxation toward monthly climatology). In contrast to the temperature equation, the relaxation term for salinity is large in many areas compared with the observed freshwater forcing (ECMWF reanalysis). For example, the annual amplitude of the simulated freshwater flux in the Gulf Stream reaches $200 \mathrm{~cm}^{\text {year }}{ }^{-1}$, compared with a freshwater annual component of $60 \mathrm{~cm}^{-1}$ year $^{-1}$ in the ECMWF reanalysis (the Gulf Stream path being too far north displaces the salinity gradient north of its normal position). This directly affects the seasonal cycle of surface salinity, with the relaxation term introducing a spurious phase difference with respect to the climatology.

Therefore we also estimated what would have been the seasonal cycle of $h_{s}$ assuming that the model salinity was the 


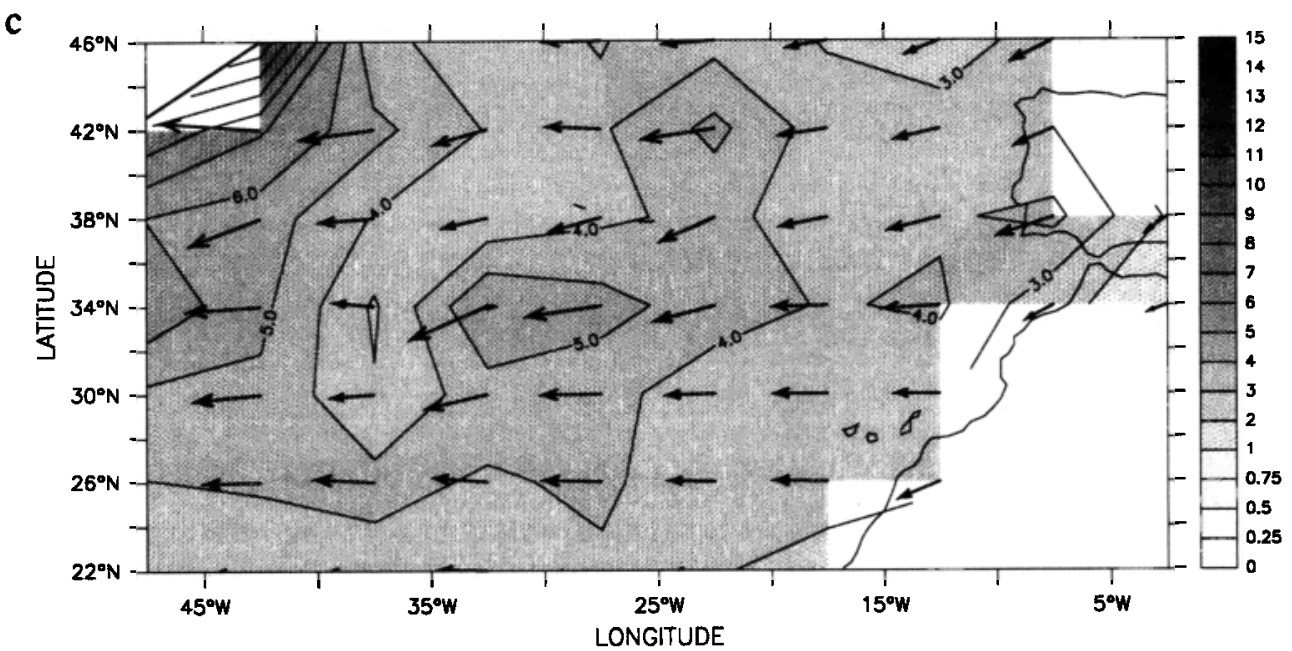

Annual harmonic, upper ocean $(0-150 \mathrm{~m})$ steric height $(\mathrm{cm})$

$\longrightarrow 5.00$

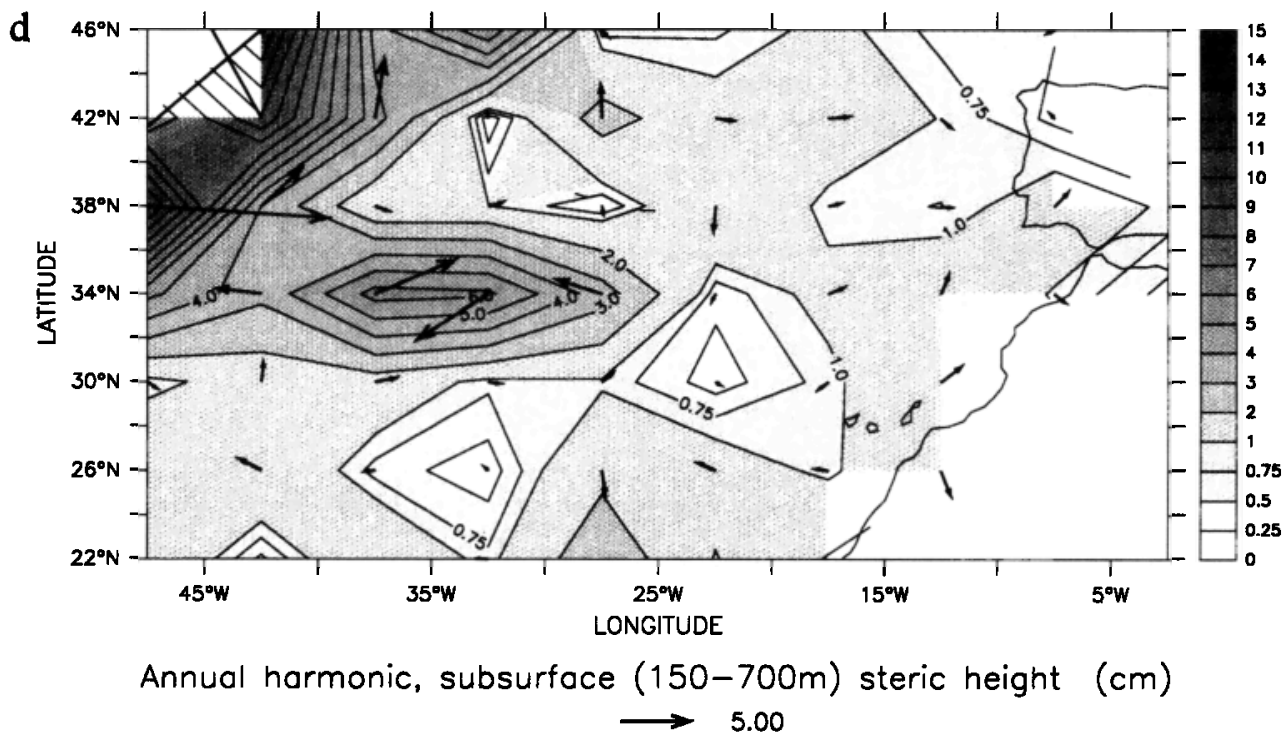

Figure 8. (continued)

climatological salinity [Levitus and Boyer, 1994] (Figure 9b). The results are quite different from the ones in the simulation. There are large values in the subpolar gyre (corresponding to a sea level maximum in the autumn, an effect nearly opposite to the one in the model), weak values south of $40^{\circ} \mathrm{N}$ and in the eastern North Atlantic, and larger values south of $20^{\circ} \mathrm{N}$. There the estimate from climatology is somewhat larger than in the simulation, but its amplitude remains $<1 \mathrm{~cm}$, except in the vicinity of South America. The position of the band of high values associated with the Intertropical Convergence Zone (ITCZ) is centered farther south in the climatology (close to $10^{\circ} \mathrm{N}$ ) than in the model (close to $15^{\circ} \mathrm{N}$ ). The climatology also suggests very small values in the eastern Atlantic but presents more spatial structure. This spatial structure might, to some extent, originate from errors, the seasonal salinity fields being not too well resolved. Estimates from the climatology in the tropics are somewhat smaller than in the simulation. This suggests that the climatology has not resolved well the large seasonal tropical variability (Dessier and Donguy [1993] provide a better sampled surface salinity seasonal climatology which has a larger seasonal amplitude than the climatology we used).
Away from major currents or upwelling areas one expects that the upper ocean salinity seasonal signal can be estimated from the net freshwater seasonal cycle. Assuming that this is the only term in the salinity equation (i.e., neglecting advection), an estimated salt content of the upper ocean can be computed, from which $h_{s}$ can be derived (Vivier et al. [1999] provide details about this calculation). This was done both with the ECMWF evaporation minus precipitaion (E-P) fields for the simulation years and with the Comprehensive Ocean-Atmosphere Data Set (COADS) E-P fields constructed by da Silva et al. [1994]. The two fields are more similar to each other than to the simulation estimate (not shown), in particular in the Gulf Stream area. There is also a maximum near $40^{\circ} \mathrm{N}$ in the central Atlantic, but this does not seem to correspond to the seasonal cycle based on the salinity fields. Nevertheless, these different estimates all suggest that the annual amplitude of the salinity term is $<0.5 \mathrm{~cm}$ in large parts of the Atlantic north of $20^{\circ} \mathrm{N}$.

\subsection{Bottom Pressure}

In the model simulation the bottom pressure $\boldsymbol{h}_{b t}$ generally presents a very weak amplitude (Figure 10) with very few regions 


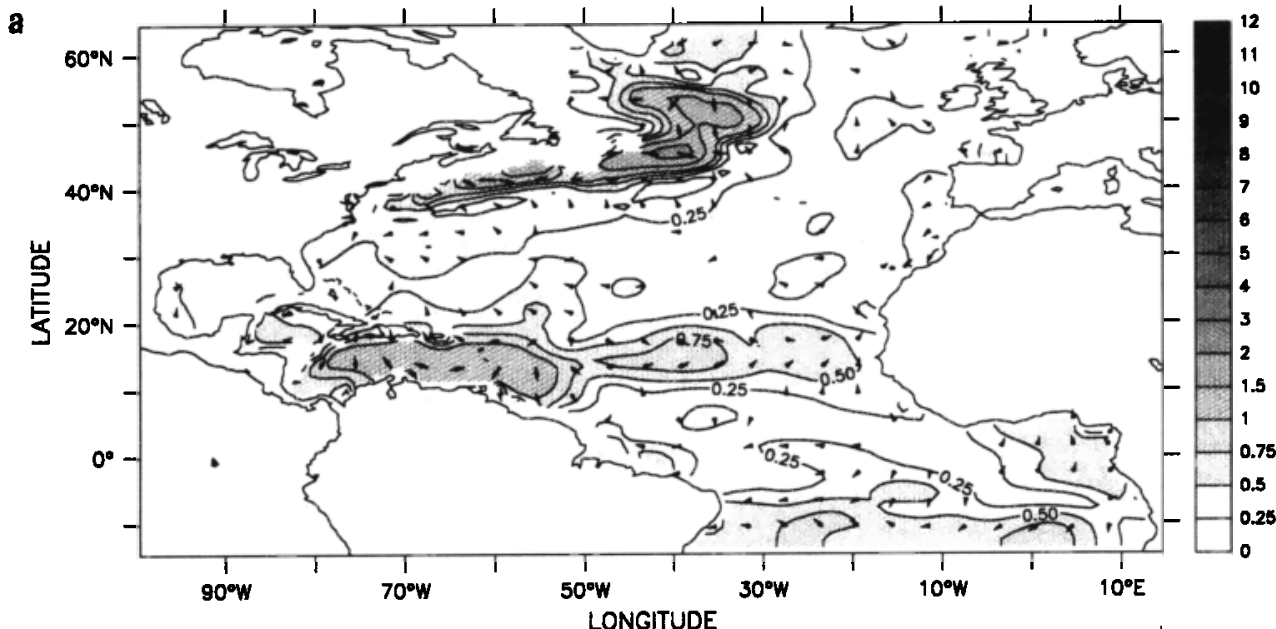

Annual harmonic, $h_{s}(\mathrm{~cm})$

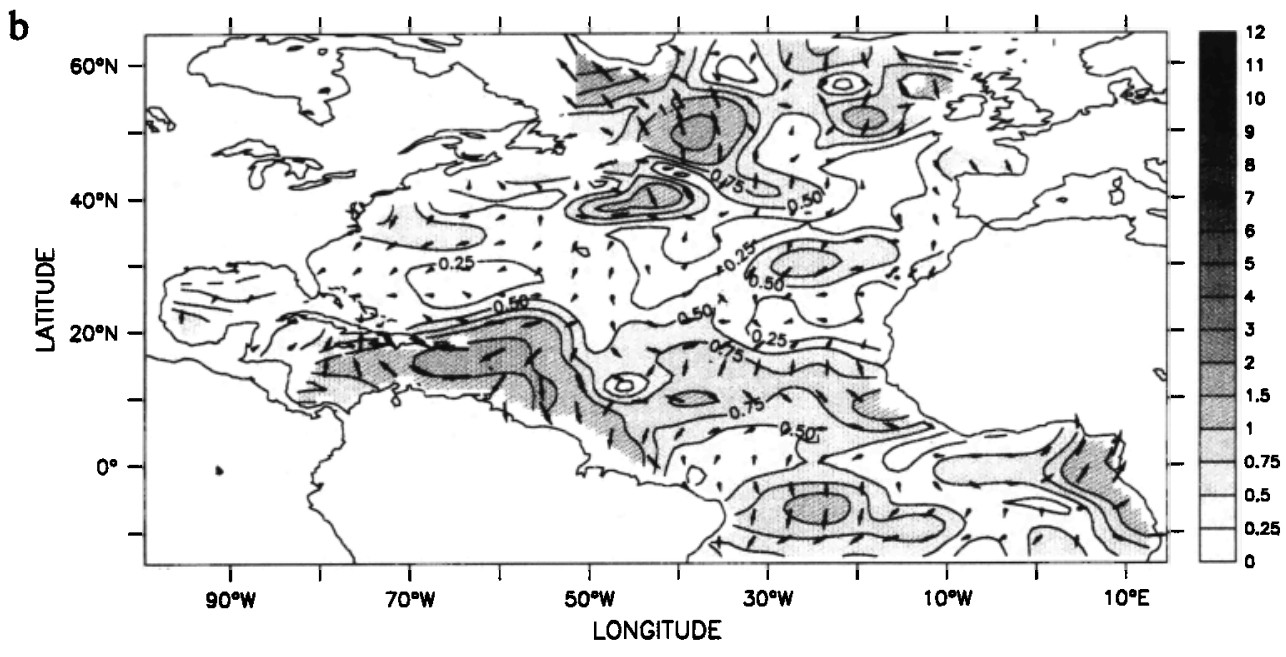

Annual harmonic, $h_{s}$ Levitus $(\mathrm{cm})$

Figure 9. (a) Same as Figure 6a but for the simulated haline contribution $h_{s}$. (b) Same as Figure 9a but for the monthly Levitus and Boyer [1994] climatology.

where it exceeds $0.5 \mathrm{~cm}$. In the western equatorial Atlantic the signal is mostly of baroclinic origin and it contributes much less to sea level seasonal cycle than the upper ocean steric variability. Elsewhere it is mostly barotropic, with an area of larger amplitudes west of Gibraltar (closed in this simulation), where the uncertainty is rather small. In the western Atlantic, part of the energy results from the large background of eddy energy in this simulation, in particular near the Gulf Stream and north of $45^{\circ} \mathrm{N}$. However, before smoothing, there was an area of amplitudes $>1$ $\mathrm{cm}$ in bottom pressure with a spatially coherent phase trapped under the Gulf Stream. There is also an area of amplitude $>1 \mathrm{~cm}$ in the Irminger Sea and south of Greenland, which extends into the Labrador Sea.

Other models have been run with somewhat different results for this term. A $1^{\circ} \times 1^{\circ}$ global OGCM has been forced with twice daily fluxes (D. Stammer, manuscript in preparation, 1999) which exhibits a low variability in $h_{b t}$ in the eastern North Atlantic but with no significant annual harmonic. In that model the annual amplitude of bottom pressure is also $<1 \mathrm{~cm}$ in the entire North Atlantic. Simulations of the wind-forced barotropic model in the Atlantic have been performed by several authors [Greatbatch and
Goulding, 1989; Ponte, 1999]. Greatbatch and Goulding [1989] found a good agreement for the annual phase between data and model simulation near the shelves. In these different simulations the seasonal amplitude of the bottom pressure is of the order of 1 $\mathrm{cm}$ near the western boundary current and is $<0.5 \mathrm{~cm}$ in the eastern North Atlantic. We obtain a phase which is nearly opposite to Ponte's [1999] results for the deep ocean. This suggests that comparison with observed bottom pressure variability should be valuable. Unfortunately, the only long bottom pressure records are in the equatorial Atlantic. These confirm that the annual bottom pressure is small (an amplitude smaller than $1 \mathrm{~cm}$ [Cartwright et al., 1987]). There is an indication in the Labrador Sea based on a comparison between the annual cycle of sea level and steric change from autonomous lagragian circulation explorer (ALACE) floats that there is a large bottom pressure signal (D. Roemmich, personal communication, 1998). Between Iceland and Newfoundland, over water deeper than $1500 \mathrm{~m}$, a comparison of the observed seasonal cycle of steric change in the upper $750 \mathrm{~m}$ and of sea level suggests a smaller bottom or deep pressure signal (the summer-winter differences in sea level and steric height are 6.8 and $5.2 \mathrm{~cm}$ 


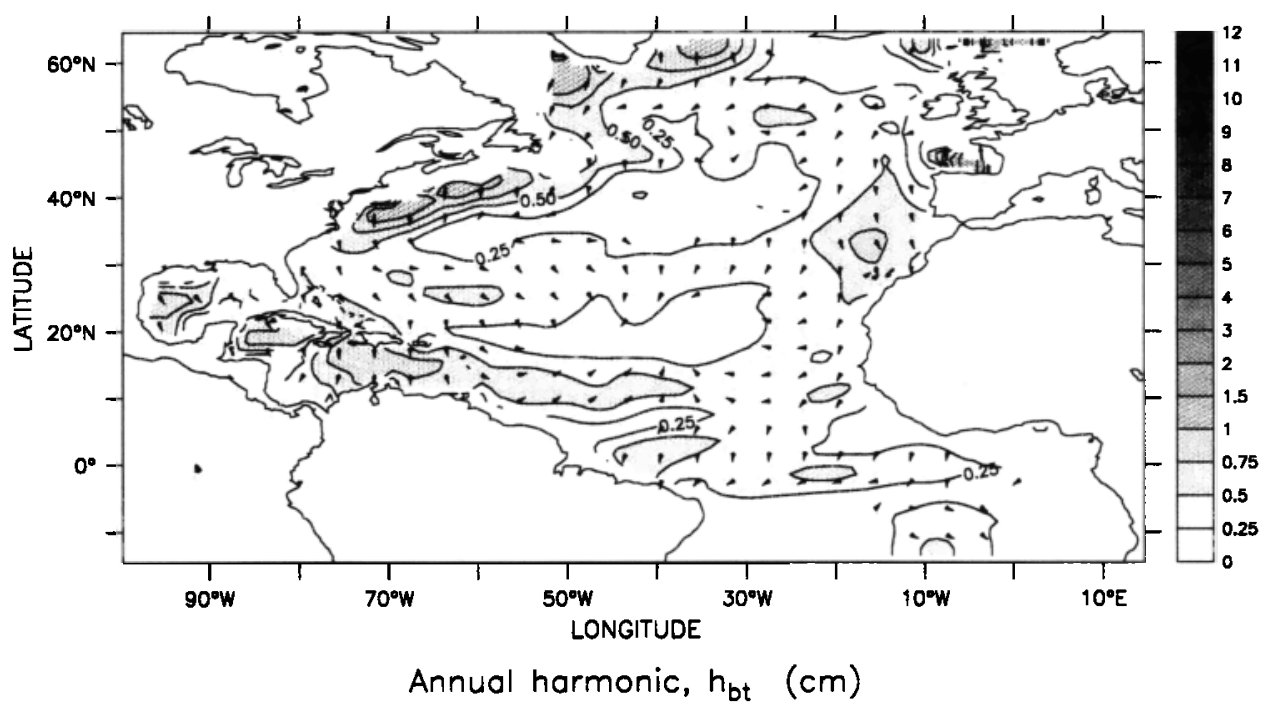

Figure 10. Same as Figure 6a but for the simulated bottom pressure component $h_{b t}$.

respectively, [Reverdin et al., 1999]). The comparison between sea level and the XBT-derived dynamic height in the eastern North Atlantic (south of $40^{\circ} \mathrm{N}$ ) certainly also suggests fairly small bottom pressure and deep steric signals. Although the annual bottom pressure signal remains therefore rather uncertain, it seems to be of a small magnitude except possibly in the northwestern Atlantic.

\section{Discussion: Comparison Between Observed Sea Level and Steric Height From Heat Flux Estimates}

The simulation confirms that away from the tropics and the Gulf Stream the annual cycle of the SSH is balanced primarily by the heating-induced upper ocean steric change. We have discussed the other terms and have found that their respective model estimates could be compared to some good results with independent observational estimates. The largest of these terms was found to be the advection term, with smaller contributions from the deep steric changes, surface salinity variability, and bottom pressure.

The model simulation shows that north of $20^{\circ} \mathrm{N}$, the seasonal sea level cycle is mainly balanced by the upper ocean steric change. In the following, we additionally address the question of whether such a balance holds when we consider the observed SSH from T/P and the heat flux taken from an operational meteorological model. Since we have seen that the different components of (2) can be simulated by our model, we shall also use these estimates to substract them from the T/P sea surface height seasonal cycle in order to compare it with the seasonal heat flux. First, we present in Figure 11 the normalized difference between the annual harmonic amplitude of the heat flux induced steric change estimated from the monthly ECMWF analysis and

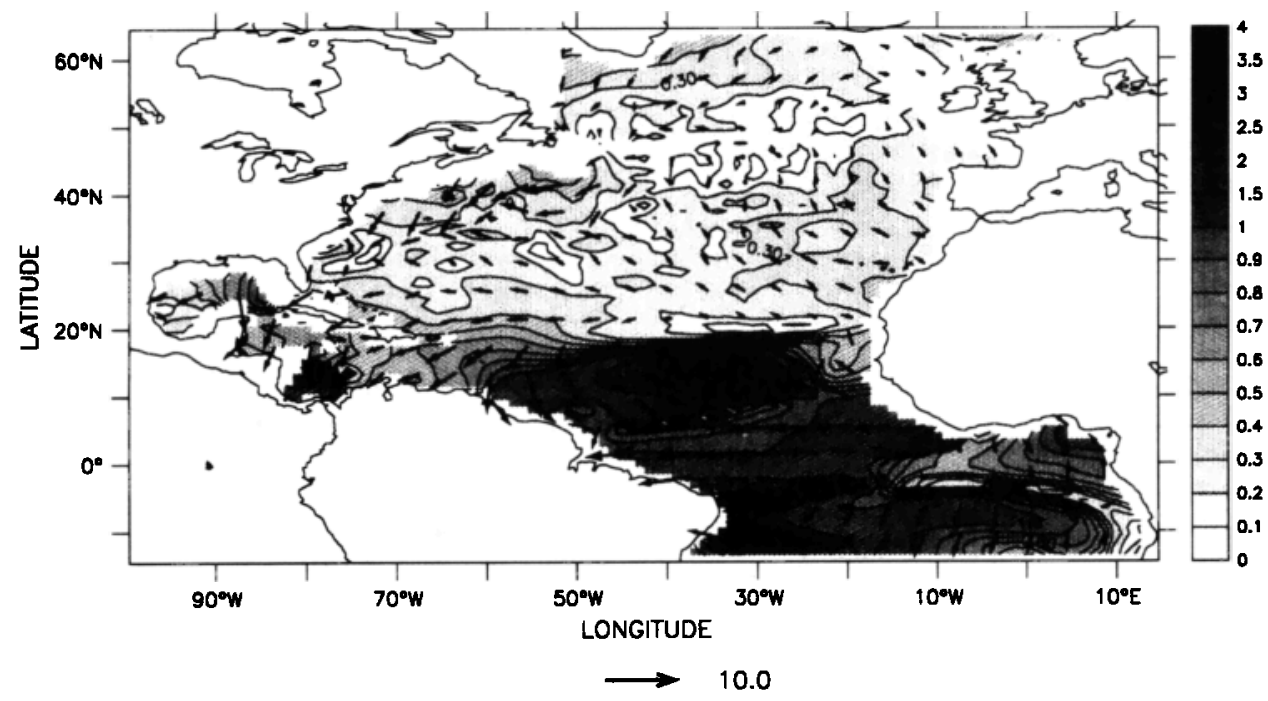

Figure 11. Difference between the T/P sea surface height and the ECMWF heat flux induced steric height annual harmonics normalized by the annual amplitude of SSH (both harmonics are relative to the October 1992 to September 1997 period). Contour lines correspond to the normalized annual amplitude harmonic of the difference. The length of the vectors is proportional to the nonnormalized difference (in $\mathrm{cm}$ ). 

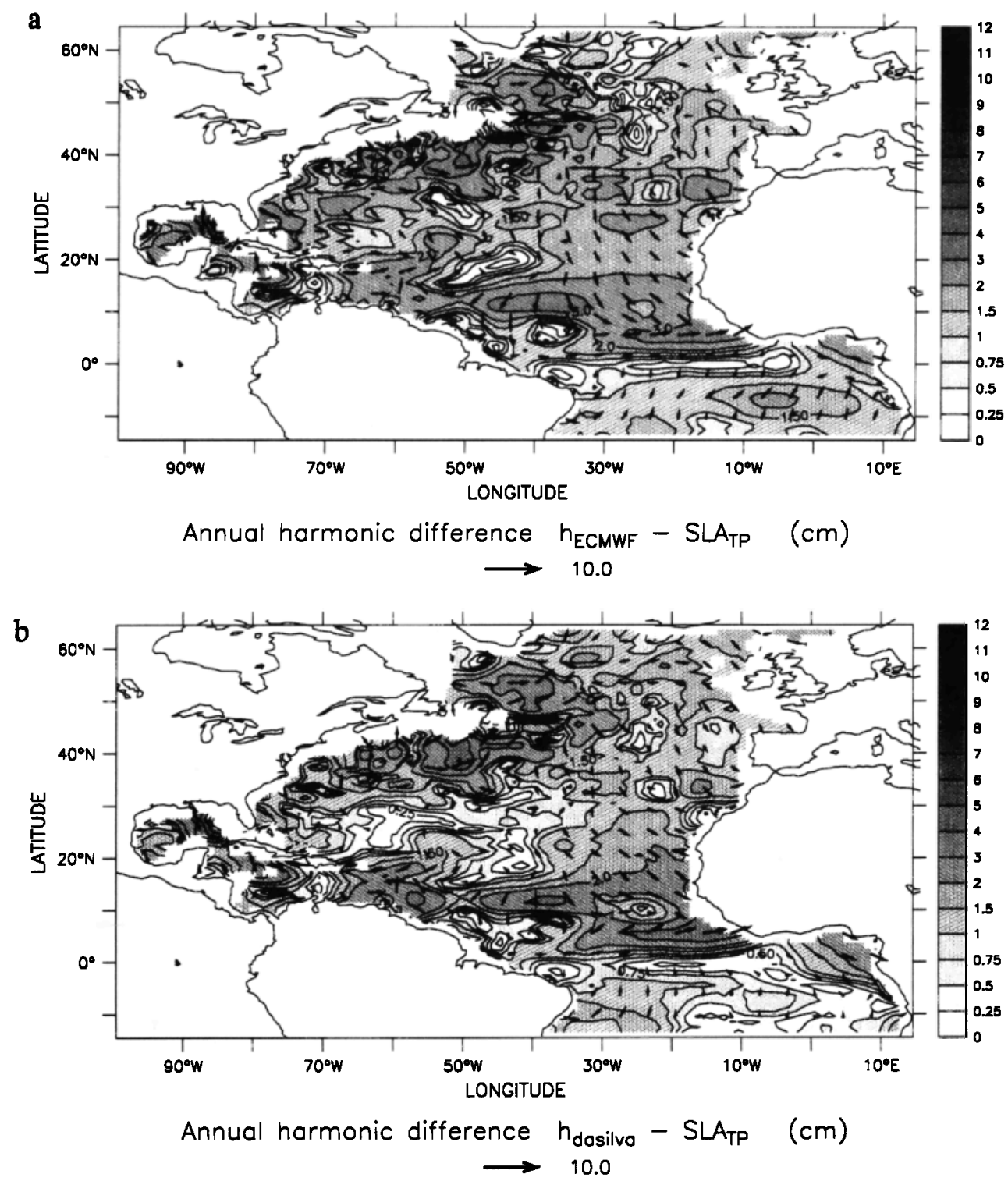

Figure 12. (a) : "Reference" estimate, the difference between the "corrected" T/P SSH and the ECMWF heat flux induced steric height annual harmonics for the October 1992 to September 1997 period. Contour lines correspond to the annual harmonic amplitude of the difference (in cm). The T/P sea level is corrected for the effect of ADV ${ }_{i} h_{b c}$, and $h_{s .}$ (b) Same as Figure 12a but the heat flux used is the da Silva et al. [1994] climatology. (c) Same as Figure 12a but an hydrological correction is applied to the T/P SSH. (d) Same as Figure 12a but an hydrological correction is applied to the T/P SSH and the heat flux used is the da Silva et al. [1994] climatology.

of the sea level from altimetry (without any correction for advection, bottom pressure, and salt storage). Both are estimated for the period from October 1992 to September 1997. The annual amplitude and phase of this residual are rather similar to the ones in the simulation (Figure $6 \mathrm{c}$ ), at least in the Gulf Stream and northwestern Atlantic and south of $20^{\circ} \mathrm{N}$. The differences are somewhat larger in the eastern North Atlantic, where they reach $30 \%$ of the annual amplitude of sea level (and have a different phase than in the simulation).

We need to evaluate whether these differences can be explained by the other terms in the equation or whether they result from errors in the heat fluxes or in sea level. For that we will use different combinations of sea level and of the other terms (right-hand side of (2)).
One example of a combination based mostly on the simulation estimates is presented on Figure 12a, where the fluxes deduced from $\mathrm{T} / \mathrm{P}$ are corrected for advection, deep ocean steric variability (both from the model simulation), and $h_{s}$ (calculated from the local freshwater budget of the ECMWF reanalysis, see section 4.4). Compared to the uncorrected fields (Figure 10), differences are much smaller in the tropics but still remain large elsewhere, in the Gulf Stream, northwestern Atlantic, and the eastern North Atlantic. In the western Atlantic this is due to the model's too northerly position of the Gulf Stream, which leads to an incorrect estimation of the annual harmonic of advection. Alternatively, one could use in situ data for estimating the horizontal advection (see section 3.3). However, when we compare the ECMWF surface heat fluxes with the combination of $T / P$ and in situ 


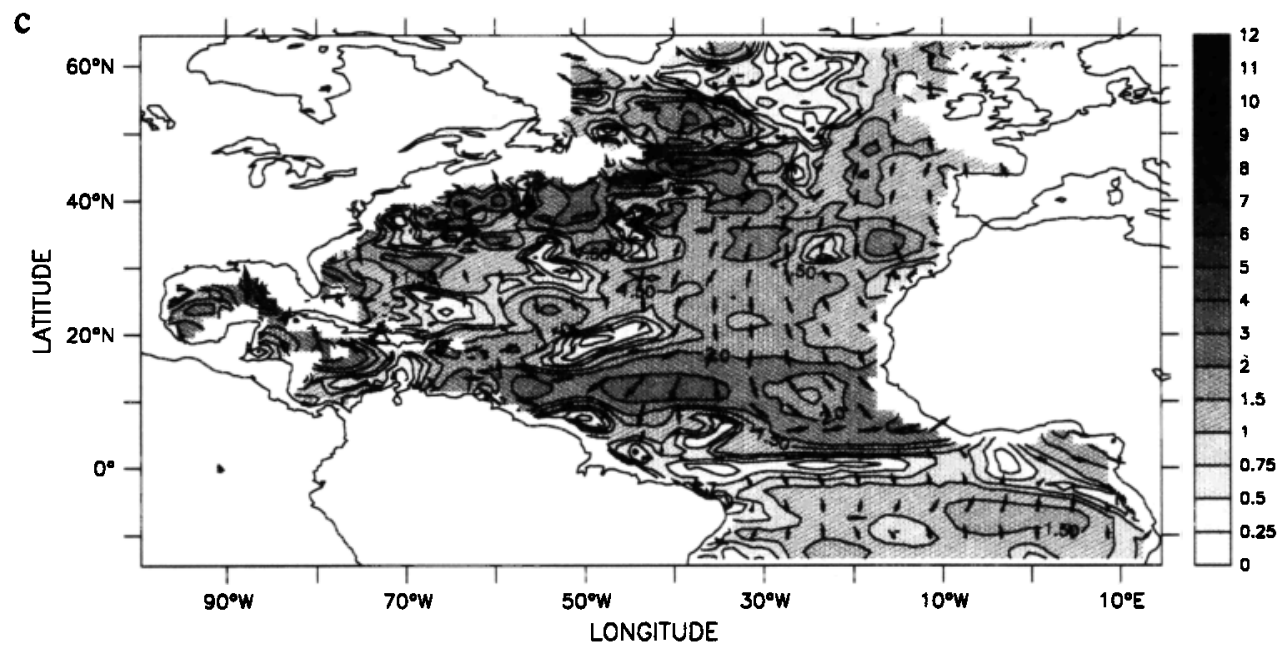

$$
\text { Annual harmonic difference } \stackrel{h_{\text {ECMWF }}-S L A_{\text {TP }} \text { hydrology }}{\longrightarrow}(\mathrm{cm})
$$

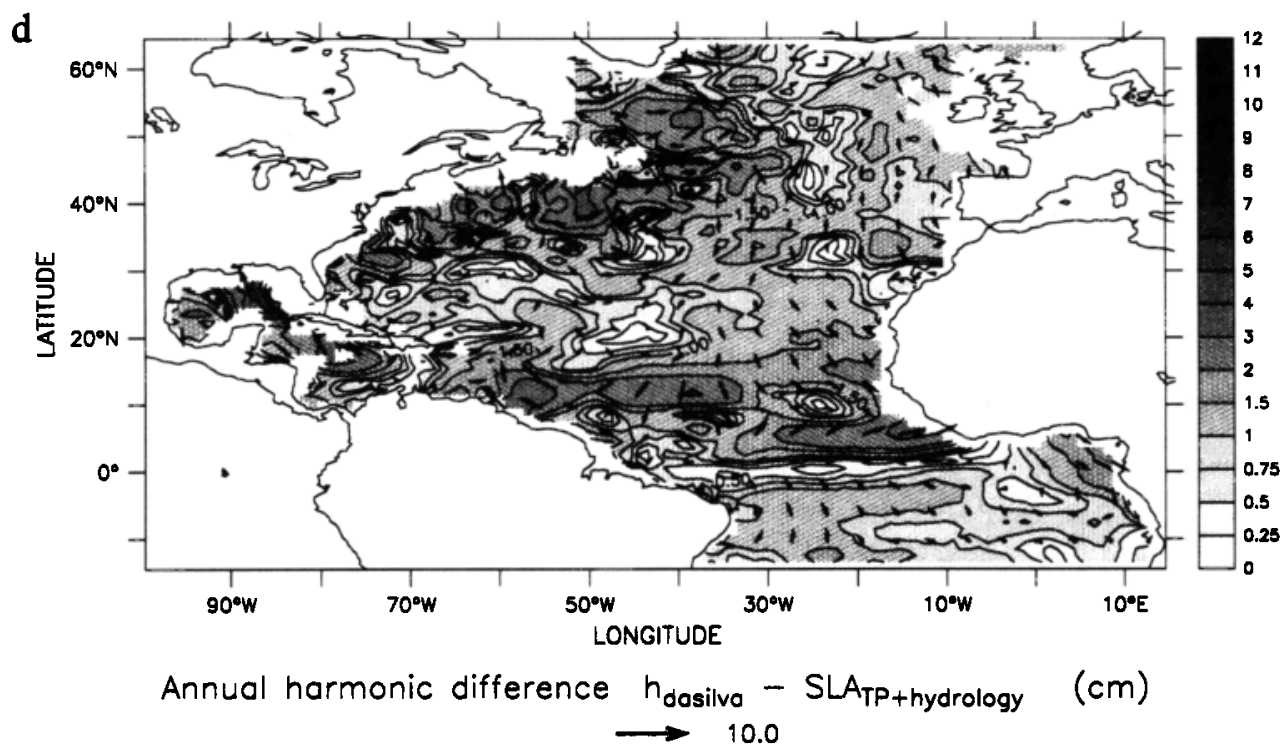

Figure 12. (continued)

estimates of horizontal advection, differences still remain large in the northwestern part of the basin (not shown). As discussed above, it is difficult to give an accurate estimate of the advection in this area on the basis of in situ data. Another area where differences remain large is the eastern Atlantic between $20^{\circ}-40^{\circ} \mathrm{N}$ and $40^{\circ}-10^{\circ} \mathrm{W}$. Other choices on the different terms do not reduce the large residual in the eastern Atlantic which roughly corresponds to an amplitude of $35 \mathrm{~W} \mathrm{~m}^{-2}$.

We will now discuss whether the total uncertainty associated with the random and/or systematic errors of the different data sets used could explain these remarkably coherent differences found in the eastern North Atlantic (see Figure 12a). We have focused on this particular region because the components of the budget are thought to be known there with the smallest uncertainties. In spite of some model shortcomings we expect advection, $h_{s,} h_{b h}$ and $h_{b c}$ to be small, as they are in the model. These errors are split into an "analysis" part, which is associated with the data analysis method (in this study, a harmonic least squares fit) and an "intrinsic" part associated with the measurement error in the altimetric data used for sea level, undersampling, and deficiencies of the physical parameterization used (bulk formulae of heat fluxes, equation of state of seawater, etc.).

The analysis error is the term easiest to evaluate. For this the covariance matrix of the residuals terms of the harmonic least squares fit gives an estimate of the ms uncertainty in $A \cos (\varphi)$ and $A \sin (\varphi)$, where $A$ is the amplitude and $\varphi$ is the phase [see, e.g., Wunsch, 1996]. The resulting error (the sum of these two terms) is displayed in Table 1 . The second component of the error budget is more difficult to estimate. Instead of trying to determine a specific error bar associated with each estimate of the budget $\left(h_{s}, h_{b o}, h_{b t}\right.$, and $\mathrm{ADV}_{T}$ in (2)), we decided to treat all errors the same way by assuming simply that the uncertainty has the same magnitude as the seasonal cycle, which is probably an overestimation of the error. Estimating the measurement error of sea level from altimetry or of heat fluxes from meteorological models is a hard task, the sources of errors being multiple and their seasonal component not well documented. An usual estimate of the rms error on T/P sea level anomaly is $2-3 \mathrm{~cm}$ on 
Table 1. Analysis of Error Budget

\begin{tabular}{lllll}
\hline & \multicolumn{2}{c}{ Analysis Errors } & \multicolumn{2}{c}{ Intrinsic Errors } \\
\cline { 2 - 5 } & rms, cm & Variance, $10^{-2} \mathrm{~cm}^{2}$ & rms, cm & Variance, $10^{-2} \mathrm{~cm}^{2}$ \\
\hline advection & 0.2 & 4 & 0.25 & 6 \\
$h_{s}$ & 0.1 & 1 & 0.25 & 6 \\
$h_{b c}$ & 0.1 & 1 & 0.5 & 25 \\
$h_{b t}$ & 0.2 & 4 & 0.5 & 25 \\
T/P sea level & 0.35 & 12 & - & - \\
$h_{Q \text { net }}$ ECMWF & 0.2 & 4 & - & - \\
$\Sigma$ variance : & & 26 & & 62 \\
Total error (analysis & & & & \\
+ intrinsic errors) & & & $880^{-2} \mathrm{~cm}^{2} \sim(0.9 \mathrm{~cm})^{2}$ & \\
\hline
\end{tabular}

The rms errors given are for each component of the annual sea level budget for the eastem North Atlantic $\left(20^{\circ}-50^{\circ} \mathrm{N}, 30^{\circ}-\right.$ $\left.5^{\circ} \mathrm{W}\right)$ : advection, haline contribution to steric height $\left(h_{s}\right)$, deep ocean steric height $\left(h_{b c}\right)$, bottom pressure component $\left(h_{b t}\right)$, sea level from TOPEX/Poseidon (T/P), and steric height induced by European Centre for Medium-Range Weather Forecasts (ECMWF) surface heat fluxes $\left(h_{Q n e t}\right)$.

the spatial scale of a few hundreds of kilometers [e.g., Cheney et $a l ., 1994]$, but the seasonal component of this error, which could result from the numerous corrections applied, is poorly known. Errors on oceanic heat fluxes from meteorological models have been estimated recently for zonal averages only [Gleckler and Weare, 1997].

Here we will try to estimate the uncertainty of altimetry and surface heat fluxes as a by-product of our error analysis. The resulting error budget is presented in Table 1. All errors are considered to be mutually uncorrelated and each variance results from the uncertainty on the phase and amplitude, that is to say on $A \cos (\varphi)$ and $A \sin (\varphi)$, where $A$ is the amplitude and $\varphi$ is the phase of the harmonic. The total uncertainty on the budget is of the order of $0.9 \mathrm{~cm}$ rms and is due to a large extent to "intrinsic" errors ( $70 \%$ of the total variance). They originate from uncertainties on the seasonal cycle of deep ocean steric height variability and bottom pressure. The harmonic least squares fit introduces only weak uncertainties, and all terms are known with nearly the same accuracy except sea level, which contains a large "noise" resulting from high-frequency variability, as indicated by the enhanced variance $\left(0.35^{2} \mathrm{~cm}^{2}\right)$. If we compare the total uncertainty found in this error analysis $(0.9 \mathrm{~cm} \mathrm{rms})$ with the difference between steric height induced by heat fluxes and altimetry (see Figure 12a and Table 2) which is $\sim 1.25 \mathrm{~cm}$ in this area, there still remains a large unexplained part. This suggests an unexplained seasonal error either in the sea level or in the oceanic heat fluxes. Its annual amplitude would be at least $\left(1.25^{<}-0.9^{2}\right)^{1 / 2}$ $\mathrm{cm} \sim 0.8 \mathrm{~cm}$, which is equivalent to $\sim 35 \mathrm{~W} \mathrm{~m}^{-2}$.

In order to attempt to resolve this discrepancy, additional tests on the accuracy of the heat fluxes and sea level products were performed. We also used heat fluxes from the National Centers for Environmental Prediction (NCEP) reanalysis, but these produced very similar results. Interestingly, using instead heat flux climatologies from volunteer observing ships (VOS) such as Esbensen and Kushnir [1981] or da Silva et al. [1994] changed to some extent the geographical distribution of the difference with altimetric estimate, especially south of $5^{\circ} \mathrm{N}$ where discrepancies are reduced. Improvement is also noticeable in the eastern North Atlantic, east of $50^{\circ} \mathrm{W}$ and between $20^{\circ}$ and $45^{\circ} \mathrm{N}$, with much less phase difference between the steric height obtained with da Silva et al. [1994] heat flux and the sea level (Figure 12b). This difference results probably to some extent from real interannual variability, but there is also the possibility of systematic errors in the ECMWF fluxes. The question of errors on the heat fluxes in the reanalyses is a very complicated issue [Gleckler and Weare, 1997]. The errors are expected to have a seasonal dependency, but the consensus is that this should be $<40 \mathrm{~W} \mathrm{~m}^{-2}$ for the seasonal cycle on the large spatial scales.

There is also the possibility of remaining seasonal biases in the sea surface height from satellite altimetry. For example, the electromagnetic bias correction has a seasonal cycle and its uncertainty probably also has a seasonal cycle. The net ocean

Table 2: Average rms Amplitude of the Difference Between the Annual Harmonic of the Sea Level From Altimetry and the Heat Flux Induced Steric Height for the Different Comparisons.

\begin{tabular}{lccccc}
\hline & $\begin{array}{c}\text { Equatorial } \\
\text { Band, } \\
10^{\circ} \mathrm{N}-10^{\circ} \mathrm{S}\end{array}$ & $\begin{array}{c}\text { Subtropical } \\
\text { Band, } \\
10^{\circ} \mathrm{N}-25^{\circ} \mathrm{N}\end{array}$ & $\begin{array}{c}\text { Gulf } \\
\text { Stream, } \\
25^{\circ} \mathrm{N}-50^{\circ} \mathrm{N},\end{array}$ & $\begin{array}{c}\text { eastern North } \\
\text { Atlantic, } \\
20^{\circ} \mathrm{N}-50^{\circ} \mathrm{N},\end{array}$ & $50^{\circ} \mathrm{W}-30^{\circ} \mathrm{W}-60^{\circ} \mathrm{N}$ \\
Corrections Applied : & 1.45 & 1.85 & 1.75 & 1.53 & 1.25 \\
\hline Reference, cm & - & - & 2.56 & 1.24 & 1.16 \\
ADV $_{T}$, in situ data, cm & 1.35 & 2.30 & 2.11 & 1.59 & 2.16 \\
Esbensen and Kushnir, cm & 1.19 & 1.55 & 1.47 & 1.28 & 1.73 \\
da Silva, cm & 1.19 & 1.70 & 1.61 & 1.39 & 0.96 \\
Hydrology, cm & 1.11 & 1.40 & 1.41 & 1.03 & 1.25 \\
da Silva \& hydrology, cm & & & & \\
\hline
\end{tabular}

The "reference" set is obtained by combining sea level from T/P with $\mathrm{ADV}_{T}$ and $h_{b c}$ from the model and $h_{s}$ deduced from the ECMWF evaporation minus precipitation (E-P) analyses. For each combination, only one component is changed, except for the last combination, where da Silva [1994] heat fluxes are used with the hydrology correction (this last component takes into account the changes in oceanic mass due to the transfers of moisture with the atmosphere and continents, after Minster et al. [1999]). Esbensen and Kushnir is from Esbensen and Kushnir [1981], and da Silva from da Silva [1994]. 
mass also changes seasonally with transfers of water with the atmosphere and with the continents, leading to a relatively uncertain though large annual amplitude of sea level of $\sim 6 \mathrm{~mm}$ with a maximum in September [Minster al., 1999]. This globa] sea level variation is referred to herein as the "hydrology" component. Including this component in our budget reduces the differences in a large part of the domain (the tropics, the Gulf Stream region and its recirculation, and north of $50^{\circ} \mathrm{N}$ ). However, the difference increases in some other regions, especially in the eastern North Atlantic, as shown on Figure 12c (to compare with Figure 12a).

These comparisons are summarized in Table 2, which gives the rms amplitude of the difference between the annual harmonics of the sea surface height and the heat induced steric height for the individual comparisons. These spatial averages were computed for specific areas: the equatorial band $\left(10^{\circ} \mathrm{S}\right.$ $\left.10^{\circ} \mathrm{N}\right)$, the subtropical band $\left(10^{\circ}-25^{\circ} \mathrm{N}\right)$, the Gulf Stream region $\left(80^{\circ}-30^{\circ} \mathrm{W}, 25^{\circ}-50^{\circ} \mathrm{N}\right)$, the eastern North Atlantic $\left(30^{\circ}-5^{\circ} \mathrm{W}, 20^{\circ}-\right.$ $50^{\circ} \mathrm{N}$ ), and north of $50^{\circ} \mathrm{N}$. The "reference" set corresponds to the ECMWF-T/P-model combination shown on Figure 12a. First, the choice of the advection component (model or in situ data) does not have a large effect on the overall comparison. Second, the choice of the heat flux data set has larger effects: both climatologies from VOS seem to reduce the misfit in the equatorial band; in addition the da Silva et al. [1994] climatology improves the comparison in all areas south of $50^{\circ} \mathrm{N}$. Further improvement is brought by the global hydrological cycle correction, which reduces discrepancies everywhere except in the eastern North Atlantic. On the basis of these encouraging results we decided to test the combination of da Silva et al. [1994] heat fluxes, model advection, and hydrological cycle correction. The result shown in Figure $12 \mathrm{~d}$ is quite remarkable with considerable improvement south of $50^{\circ} \mathrm{N}$ compared to the other cases. At this level the results are coherent with the expected uncertainties (see Table 1), implying a seasonal error of $0.2 \mathrm{~cm}$ (equivalent to $\sim 10$ $\mathrm{W} \mathrm{\textrm {m } ^ { - 2 }}$ ) that is quite reasonable. This raises the issue of whether it is just by chance that the results are more reasonable when using a heat flux climatology than the actual heat fluxes from meteorological models. Such questions on the accuracy of the heat fluxes have been raised by the conclusions of studies of other OGCM simulations studies [e.g., Stammer et al., 1996; Chao and $F u, 1995$ ] in so far as the seasonal cycle amplitude of the simulated sea level is often too low when compared with the observations. This, however, could also result from defects in the models due, for example, to the parameterization of vertical mixing or lateral diffusivity or the too coarse vertical resolution. Such potential error sources are considerably reduced in the present study by using a higher-resolution OGCM with a more appropriate parameterization of turbulent mixing.

Although uncertainties subsist on some components of the sea level budget (2), this study supports the hypothesis that the heat flux products are the most likely source for the discrepancy. In particular, the spatially coherent phase difference between heat flux induced steric change and sea level (see Figure 12a) could be due to deficiencies of the physical parameterizations used in meteorological models. Studies suggest that errors resulting from the cloud schemes are present in the radiative fluxes of ECMWF and NCEP reanalyses, which affects the seasonal cycle of the net heat flux [Wild et al., 1998; Jacob, 1999] and, indirectly, the surface winds as well as the latent and sensible fluxes [Bergman and Hendon, 1998].

We have found differences between the model estimation and the data for the terms of the sea surface height budget that suggest possible shortcomings of the model simulation. Of course, part of the difference originates from the different periods simulated and observed. However, we think that the annual variability of these different terms should have remained fairly stationary, as heat fluxes from the reanalysis suggest a rather similar seasonal variability for the two periods. On the other hand, $h_{b c}$ and $h_{b t}$ annual cycles will be largely a response to the seasonal changes in the wind and its curl. These can have a significant year to year variability (mostly due to the winter season), for example, associated with the North Atlantic Oscillation. However, there is certainly also an effect of the model shortcomings. Although the OGCM is "eddy-permitting," the resolution is not fine enough to correctly reproduce the eddy variability generated, in particular, by baroclinic instability. This is true both in the eastern North Atlantic and in more energetic regions (in the Gulf Stream). The poor representation of eddy processes, fronts, and boundary currents probably impacts the model heat transport and therefore the advection term [Bryan et al., 1998; Böning and Budich, 1992].

We could not check the bottom pressure variability from data, but from our model result it seems to be small in the eastern Atlantic. It could, however, be larger near topographic features or in the northwestern Atlantic according to barotropic models of the response to wind forcing.

\section{Conclusions}

We have presented in this study a synthetic view of all the components having an impact on the sea level variability at the seasonal timescale. This confirms that in large parts of the North Atlantic the sea surface height seasonal cycle is mainly caused by the steric changes induced by the heat fluxes, in agreement with Stammer's [1997] model study of the global oceans. The other terms contribute to a smaller extent to the SSH budget. However, their importance might not be negligible in the tropics (advection and salt budget) and near the western boundary current (advection and bottom pressure). The model reproduces well the magnitude of each component when compared with estimates based on in situ measurements (particularly in the eastem North Atlantic), but we think that some terms in our sea level budget are somewhat dependent on the model and boundary condition used. The phase of the annual component of $h_{s}$ (related to the salt content of the water column) is probably uncertain because E-P fields are not well known. The bottom pressure cannot be compared with in situ measurements and may contain a residual signal related to the model spin-up. Deep ocean steric height seasonal change may also be different when using an isopycnal rather than a horizontal diffusion in the OGCM.

In view of these model results we are surprised by the difference found between heat flux induced annual steric height variability and the observed SSH from altimetry. In particular, east of $40^{\circ} \mathrm{W}$ and between $20^{\circ}$ and $40^{\circ} \mathrm{N}$, this difference exceeds the uncertainty associated with the residual components of the sea level budget. A correction for the effect of the global seasonal hydrological cycle on mean sea level was included in our budget, showing the sensitivity of SSH to this term. The better agreement found when climatological [da Silva et al., 1994] heat fluxes are used instead of the ECMWF analyzed fluxes might not be coincidental and suggests the possibility of deficiencies in the physical parameterizations used in meteorological models (here ECMWF heat fluxes for October 1992 to September 1997). 


\section{Appendix}

Here we discuss the assumption that the variation of the vertical mean thermal expansion coefficient $A$ does not contribute significantly to the average seasonal cycle. We define $A$ such as to link the heat content $T$ of a water column to its "thermosteric" height $h_{T}$ (steric height taking into account the anomalies of temperature only) by the following equation: $h_{T}=A T$, where $h$ is the vertical integral of $\rho^{\prime}(t) / \rho_{o}$ from surface to $H_{\max }$ (the winter mixed layer depth), where $\rho^{\prime}(t)$ is the density anomaly due to temperature $t$ and $\rho_{o}$ is a mean reference density. $T$ is the vertical integral of temperature $t$ from surface to $H_{\max }: T=\int t d z$, and $A=$ $h_{T} / T$ is therefore by definition a vertically integrated expansion coefficient taking into account the variations of the thermal expansion from the surface to $H_{\max }$.

A calculation of $A$ based on the monthly Levitus and Boyer [1994] climatology shows that this coefficient has a strong annual cycle. It is, however, possible to ignore these annual fluctuations. Let's split $h, A$, and $T$ in a mean plus a fluctuating part (mostly annual): $A=a_{o}+a_{s}+a^{\prime}, T=T_{o}+T_{s}+T^{\prime}$, and $h_{T}=h_{o}+h_{s}+h^{\prime}$, where index $o$ refers to the time average, $s$ refers to the annual cycle, and primes refer to the residual variability. When one considers only the annual component (annual period) of equation $h=A T$, one obtains

$$
h_{s}=a_{o} T_{s}+a_{s} T_{o}+\left(a^{\prime} T^{\prime}\right)_{s}
$$

According to the monthly Levitus and Boyer [1994] climatology, $a_{s}$ is strongly correlated to $T_{s}$ (the correlation exceeds 0.9 over the whole North Atlantic) and can be expressed as $a_{s}=K T_{s}$, where $K$ is a coefficient of proportionality varying spatially. Furthermore, $\left(a^{\prime} T^{\prime}\right)_{s}$ is small for the Levitus and Boyer [1994] climatology compared to the other terms and can be neglected in (A1).

Equation (A1) then reduces to $h_{s}=\left(a_{o}+K T_{o}\right) T_{s}$, where $\left(a_{o}\right.$ $\left.+K T_{o}\right)$ is the constant expansion coefficient used in our study. This was checked with the Levitus and Boyer [1994] climatology: the relative error of the annual harmonic amplitude is found to be $<1 \%$ and phase uncertainty is $<3^{\circ}$.

Acknowledgments. The authors thank Jean-François Minster for having initiated this study. ECMWF reanalysis surface fluxes were kindly provided by Météo France (AVISO vent-flux database). OGCM simulations have been performed while N.F. was visiting IfM Kiel. The altimeter analyses of sea surface height were produced by CLS Space Oceanography Division as part of the Environment and Climate EC AGORA (ENV4-CT9560113) and DUACS (ENV4-CT96-0357) projects and kindly provided by Pierre-Yves Le Traon from CLS.

\section{References}

Alexander, M.A., and C. Deser, A mechanism for the recurrence of winter time midlatitude SST anomalies, J. Phys. Oceanogr.. 25, 122-137, 1995.

Barnier, B., L. Siefridt, and P. Marchesiello, Surface thermal boundary condition for a global ocean circulation model from a three-year climatology of ECMWF analyses, J. Mar. Syst., 6, 363-380, 1995.

Bergman, J. W., and H. H. Hendon, The impact of cloud-field errors on radiative heating in the NCEP/NCAR reanalysis data, in Proceedings of the First WCRP International Conference on Reanalyses, rep.104. pp. 255-258, World Clim. Res. Program, Geneva, Switzerland, 1998.

Blanke, B., and P. Delecluse, Variability of the tropical Atlantic simulated by a general circulation model with two different mixed-layer physics, J. Phys. Oceanogr., 23, 1363-1388, 1993.

Böning, C.W., and R. G. Budich, Eddy dynamics in a primitive equation model: Sensitivity to horizontal resolution and friction, $J$. Phys. Oceanogr, 22, 361-381, 1992.

Bryan, F. O., and W. R. Holland, A high resolution simulation of the windand thermohaline-driven circulation in the North Atlantic Ocean, in Parameterization of Small-Scale Processes: Proceedings of 'Aha
Huliko'a, Howaiian Winter Workshop, edited by P. Müller and D. Henderson, pp. 99-115, Hawaii Inst. Geophys., Honolulu, 1989.

Bryan, F. A., R. D. Smith, M. E. Maltrud, and M. W. Hech, Modeling the North Atlantic circulation: From eddy permitting to eddy resolving paper presented at Conference on Ocean Circulation and Climate, World Ocean Circulation Experiment, Halifax, Nova Scotia, Canada, May 24-29 1998.

Cartwright, D. E., R. Spencer, and J. M. Vassie, Pressure variations on the Atlantic equator, J. Geophys. Res., 92, 725-741, 1987.

Cayan, D., Latent and sensible heat fluxes anomalies over the northern oceans: The connection to monthly atmospheric circulation, J. Clim., $5,354-369,1992$.

Chambers, D. P., B. D. Tapley, and R. H. Stewart, Long-period ocean heat storage rates and basin-scale heat fluxes from TOPEX, J. Geophys. Res., 102, 10,525-10,533, 1997.

Chao, Y., and L.-L. Fu, A compariso between the TOPEX/Poseidon data and a global ocean general circulation model during 1992-1993, J. Geophys. Res., 100, 24,965-24,976, 1995.

Cheney, R., L. Miller, R. Agreen, N. Doyle, and J. Lillibridge, TOPEX/Poseidon: The 2-cm solution, J. Geophys. Res, 99, 24,555$24,563,1994$.

da Silva, A. M., C. C. Young, and S. Levitus, Atlas of Marine Surface Data, vol. 2, 83 pp., U.S. Gov. Print. Off., Washington, D. C., 1994.

Dessier, A., and J. R. Donguy, The sea surface salinity in the tropical Atlantic between $10^{\circ} \mathrm{S}$ and $30^{\circ} \mathrm{N}$. Seasonal and interannual variations (1977-1989), Deep Sea Res., Part I, 4I, 81-100, 1993.

Dorandeu, $J$., and P. Y. Le Traon, Effects of global mean atmospheric pressure variations on mean sea level changes from TOPEX/Poseidon, J. Atmos. Ocean. Technol., 16, 1279-1283, 1999.

Dynamics of North Atlantic Models (DYNAMO) Group, Dynamics of North Atlantic Models: Simulation and assimilation with high resolution models, Ber. 294, 334 pp., Inst. für Meereskunde and der Christian Albrechts Univ. Kiel, Kiel, Germany, 1997.

Eanes, R. J., and S. V. Bettadpur, The CSR 3.0 global ocean tide model, CSR-TM-5-06, Cent. for Space Res., Univ. of Tex. at Austin, 1995.

Esbensen, S. K., and Y. Kushnir, The heat budget of the global ocean: An atlas based on estimates from surface marine observations, Rep. 29, Clim. Res. Inst., Oreg. State Univ., Corvallis. 1981.

Fukumori, I., R. Raghunath, and L.-L. Fu, Nature of global large-scale sea level variability in relation to the atmospheric forcing: A modeling study, J. Geophys. Res., I03, 5493-5512, 1998.

Gaspar, P., F. Ogor, P. Y. Le Traon, and O. Z. Zanife, Estimating the sea state bias of the TOPEX and Poseidon altimeters from crossover differences, J. Geophys. Res., 99, 24,981-24,994, 1994.

Gill, A. E., and P. P. Niiler, The theory of the seasonal variability in the oceans, Deep Sea Res., 20, 141-177, 1973.

Gleckler, P. J., and B. C. Weare, Uncertainties in global ocean surface heat flux climatologies derived from ship observations, J. Clim., 10, 2764$2781,1997$.

Greatbatch, R. J., and A. Goulding, Seasonal variations in a linear barotropic model of the North Atlantic driven by the Hellerman and Rosenstein wind stress field, J. Phys. Oceanogr., 19, 572-595, 1989.

Han, Y.-J., A numerical world ocean circulation model, part II, A baroclinic experiment, Dyn. Atmos. Oceans, 8, 141-172, 1983.

Hellerman, S., and M. Rosenstein, Normal Monthly wind stress over the world ocean with errors estimate, J. Phys. Oceanogr., 13, 1093-1104, 1983.

Jacob, C., Cloud cover in the ECMWF reanalysis, J. Clim., 12, 947-959, 1999.

Lamb, P. J., On the mixed-layer climatology of the north and tropical Atlantic, Tellus, Ser. A, 36, 292-305, 1984.

Le Traon, P.-Y., F. Nadal, and N. Ducet, An improved mapping method of multisatellite Altimeter data, J. Atmos. Ocean. Technol., 15, 522-534, 1997.

Levitus, S., Climatological atlas of the world ocean, NOAA Prof. Pap. 13. 173 pp., U. S. Govt. Print. Off., Washington, D. C., 1982.

Levitus, S., Annual cycle of temperature and heat storage in the world ocean, J. Phys. Oceanogr., 14, 727-746, 1984.

Levitus, S., and T. Boyer, World Ocean Atlas, vol. 4, Temperature. NOAA Atlas NESDIS 4, 129 pp., Natl. Oceanic and Atmos. Admin., Silver Spring, Md., 1994.

Merle, J., Seasonal heat budget in the equatorial Atlantic Ocean, J. Phys. Oceanogr., 10, 464-469, 1980.

Merle, J., and S. Amault, Seasonal variability of the surface dynamic topography in the tropical Atlantic Ocean, J. Mar. Res., 43, 267-288, 1985 .

Minster, J. F., A. Cazenave, Y. V. Serafini, F. Mercier, M. C. Gennero, and $P$. Rogel, Annual cycle in mean sea level from TOPEX-Poseidon and ERS-1: Inference on the global hydrological cycle, Global Planet. Change, 20, 57-66, 1999.

Moisan, J. R., and P. P. Niiler, The seasonal heat budget of the North Pacific: Net heat flux and heat storage rates (1950-1990), J. Phys. Oceanogr., 28, 401-421, 1998.

New, A. L., R. Bleck, Y. Jia, R. Marsh, M. Huddleston, and S. Barnard, An isopycnic model study of the North Atlantic, part I, Model experiment, J. Phys. Oceanogr, 25, 2667-2699, 1995. 
Niiler, P. P., A. S. Sybrandy, K. Bi, P. M. Poulain, and D. Bitterman, Measurements of the water-following capability of holey-sock and TRISTAR drifters, Deep Sea Res., Part I, 42, 1951-1964, 1995.

Oschlies, A., and V. Garcon, An eddy-permitting coupled biologicalphysical model of the North Atlantic, 1, Sensitivity to advection nummerics and mixed layer physics, Global Biogeochem. Cycles, 13, 135-160, 1999.

Oschlies, A., and J. Willebrand, Assimilation of Geosat altimeter data into an eddy-resolving primitive equation model of the North Atlantic Ocean, J. Geophys. Res., 101, 14,175-14,190, 1996.

Patullo, J., W. Munk, R. Revelle, and E. Strong, The seasonal oscillation in sea level, J. Mar. Res., 14, 88-155, 1955.

Ponte, R., A preliminary model study of the large-scale seasonal cycle in bottom pressure over the global ocean, J. Geophys. Res., I04, 1289 $1300,1999$.

Reverdin, G., N. Verbrugge, and H. Valdimarson, Upper ocean variability between Iceland and Newfoundland 1993-1997, J. Geophys. Res., in press, 1999.

Reynolds, R. W., and T. M. Smith, A high-resolution global sea surface temperature climatology, J. Clim., 8, 1571-1583, 1995.

Schlax, M. G., and D. B. Chelton, Aliased tidal errors in TOPEX/Poseidon sea surface height data, $J$. Geophys. Res., 99, 24,761-24,775, 1994.

Stammer, D., Steric and wind-induced changes in TOPEX-Poseidon largescale sea surface topography observations, J. Geophys. Res., 102, 20,987-21,009, 1997.

Stammer, D., R. Tokmakian, A. Semtner, and C. Wunsch, How well does a $1 / 4^{\circ}$ global circulation model simulate large-scale oceanic observation?,J. Geophys. Res., 101, 25,779-25,794, 1996.

Stramma, L., and G. Siedler, Seasonal changes in the North Atlantic subtropical gyre, J. Geophys. Res., 93, 8111-8118, 1988.

Tabata, S., B. Thomas, and D. Ramsden, Annual and Interannual variability of steric sea level along line $P$ in the northeast Pacific Ocean, J. Phys. Oceanogr., 16, 1375-1398, 1986.

van Meurs, $P$., and $P$. P. Niiler, Temporal varibility of the large-lcale geostrophic surface velocity, J. Phys. Oceanogr., 27, 2288-2297, 1997.

Vivier, F., K. A. Kelly, and L. A. Thompson, Contributions of wind forcing, waves, and surface heating to sea surface height observations in the Pacific Ocean. J. Geophys. Res, 104, 20,767-20,788, 1999.

Wang, L., and C. Koblinsky, Annual variability of the subtropical recirculations in the North Atlantic and North Pacific: A TOPEX/Poseidon study, J. Phys. Oceanogr., 26, 2462-2479, 1996.

Wild, M., A. Ohmura, and H. Gilgen, Assessment of the ECMWF reanalysis radiative fluxes using surface observations, in Proceedings of the First WCRP International Conference on Reanalyses, rep. 104, pp. 69-73, World Clim. Res. Program, Geneva, Switzerland, 1998.

Wunsch, C., The Ocean Circulation Inversion Problem, 442 pp., Cambridge Univ. Press, New York, 1996.

N. Ferry and G. Reverdin, Laboratoire d'Etudes en Géophysique et Océanographie Spatiales, UMR5566 CNES/CNRS/UPS, 14 Avenue Edouard Belin, 31401 Toulouse Cedex 4, France. (nicolas.ferry@enes.fr) A. Oschlies, Institut für Meereskunde an der Universität Kiel, 20, Düsternbrooker Weg, 24105, Kiel, Germany.

(Received October 21, 1998; revised October 1, 1999; accepted October 25, 1999.) 